\begin{tabular}{|c|c|c|} 
Fansoura University & Falty of Engineering \\
Mansoura Engineering Journal &
\end{tabular}

\title{
Rehabilitation of Existing Educational Buildings to Enhance Sustainability
}

\author{
Mohamed Elsadat Assasa*, Alaa Elsayed Fared and Algndy Shaker Algndy
}

\begin{tabular}{|l|}
\hline KEYWORDS: \\
Rehabilitation, \\
Educational Building, \\
Sustainability, Energy \\
Rationalization \\
\end{tabular}

Abstract-Coinciding with the increasing danger and negative effects of the
built-up urban environment towards the environment, the depletion of its
natural resources and the high costs of electricity consumption, the primary
challenge facing the urban sectors is the production of buildings with energy and
water efficiency and an optimal use of natural resources and building materials,
education institutions are generally considered the nucleus of influence Society
towards sustainable intellectual transformation and raising awareness in society
of the importance of applying the concept of sustainability, not only through
educational curricula taught, but through application to existing buildings
surrounding them, these buildings need to be rehabilitated to improve and
improve their efficiency.

2

يهدف البحث إلي محاولة الوصول لإستر اتيجيات عملية لتطبيق مفهوم

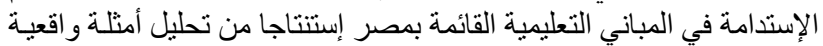

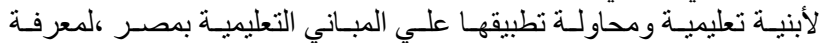

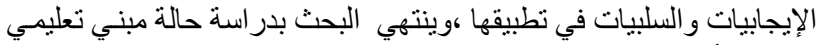

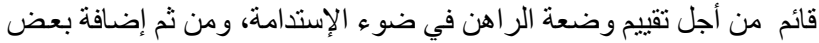

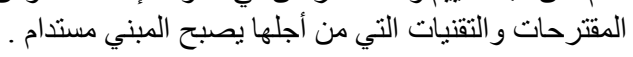

$$
\text { 3. إعتمد البحث علي المناهج الاتية }
$$

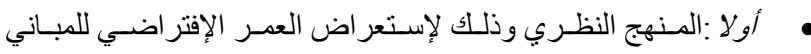

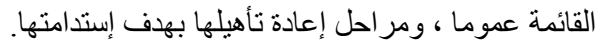

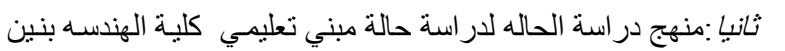

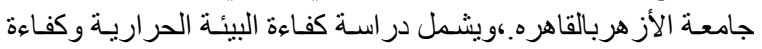

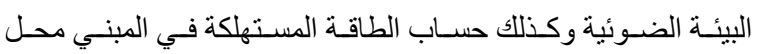
الدر اسة وحلول تقليلها.

$$
\text { • - أولام) المنهج النظري الإفتراضي للمباني وأنواعه }
$$

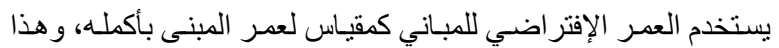

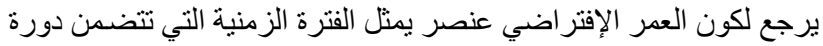

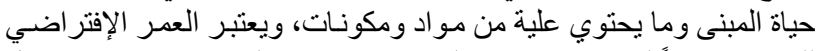

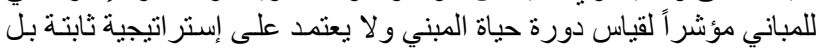

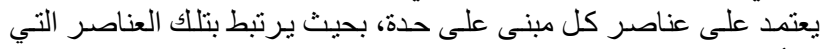

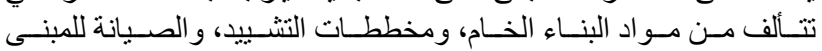

بأكملة. (1) بن

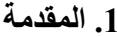

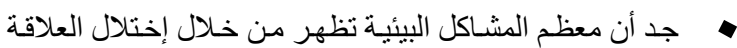

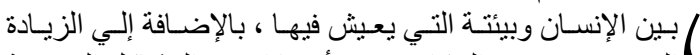

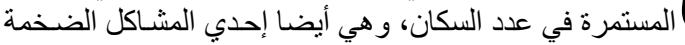

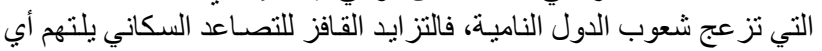

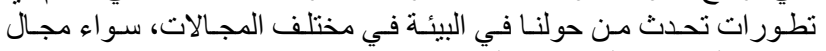

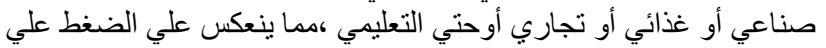

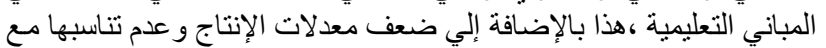

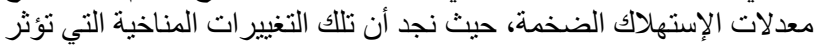

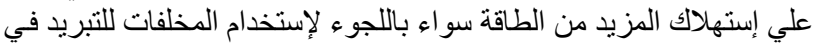

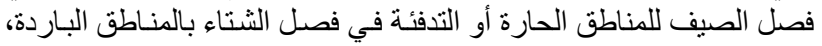

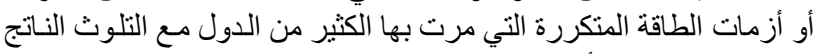

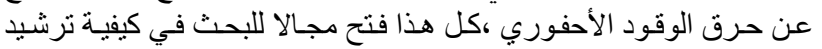

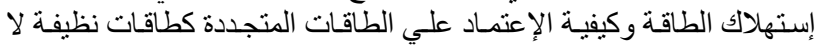

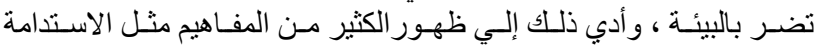

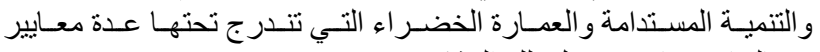
ومعالجات تناهم في حل تللك المشكلات.

Received: (08 September, 2020) - Revised: (16 March, 2021) Accepted: (31 March, 2021)

*Corresponding Author: Mohamed Elsadat Assasa Instructor at Architecture Engineering Mandala Institute Engineering, (e-mail: mohamadalsadat88@gmail.com).

Alaa Elsayed Fared, Professor at Architecture Engineering at Faculty of engineering alazhar university (e-mail: author@ boulder.nist.gov).

Algndy Shaker Algndy Professor at Architecture Engineering at Faculty of engineering alazhar university (e-mail: algndyshaker@yahoo.com). 
(1-1-2) إعادة التأهيل الطفيف: ويشـل إجـر اء إصـلاحات في الداهانات،

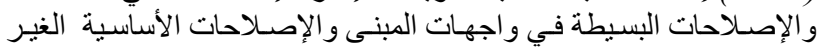
معقدة.

(2-1-2) إعـادة التأهيل المتوسط: ويثـمل إسـتبدال الـدهانات و الأرضـيات

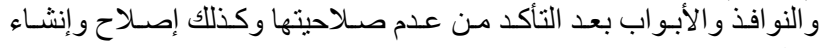

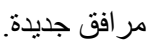
(3-1-2) إعـادة التأهيل واسـع المجـال: ويثــل إسـتبدال الجـدران للمبـاني

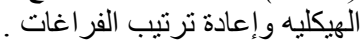

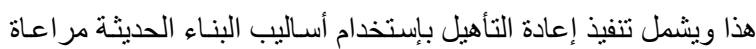

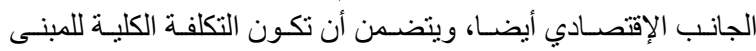

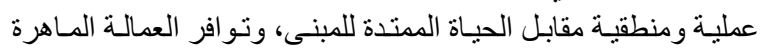

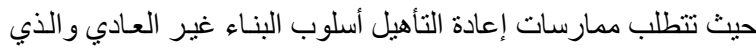
يحتاج إلى عمال منفذين ذو كفاءة وخبرة في البناء. ويري البحث أنة يمكن تعريف مصطلح إعادة التأهيل على أنة مفهوم

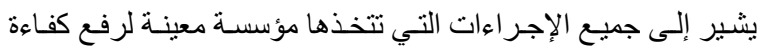

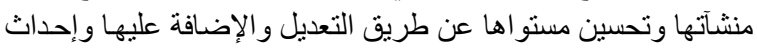

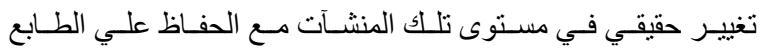
المعماري.

مما سبق يمكن إستنتاج أن عملية إعادة تأهيل المباني عملية مركبة،

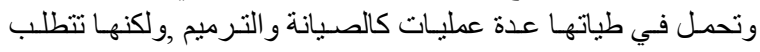

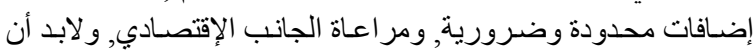
تتنهي تللك الإجر اءات برفع كفاءة المبني وتحسين آدائه

3- الوضع الحالي لإستهلاك الطاقة في مصر :-(8)

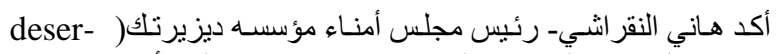

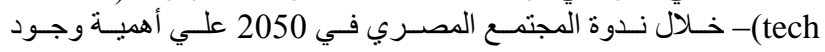

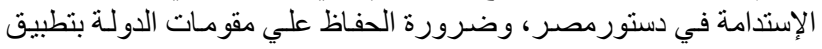

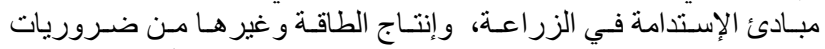

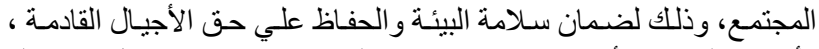

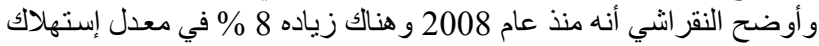

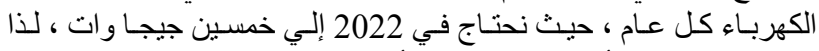

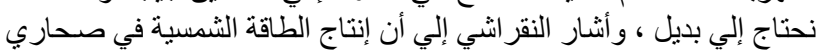

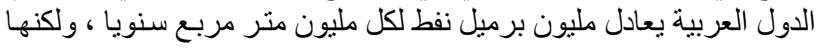
لم نستغلها حتي الآن.

4- العو امل المؤثرة في إستهلاك الطاقة في المباني:- (9)

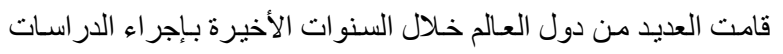

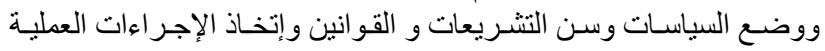

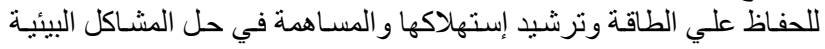

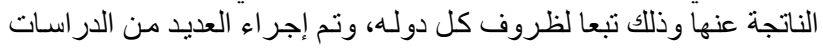

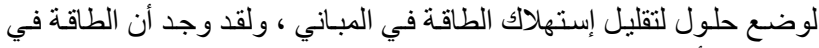

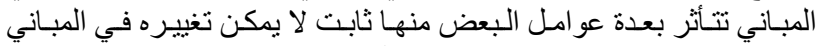

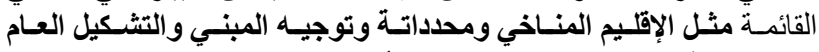

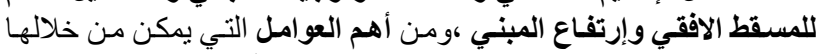

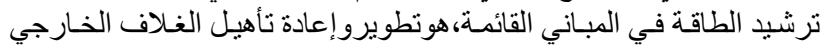

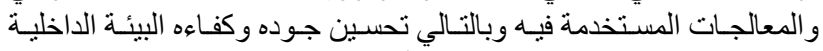

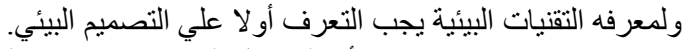

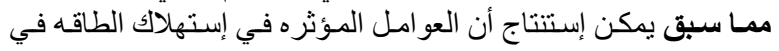

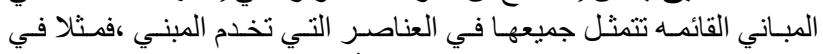

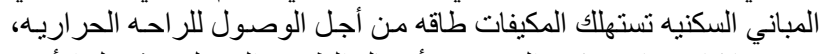

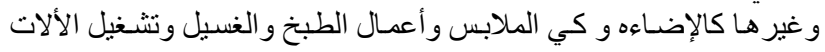

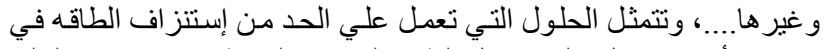

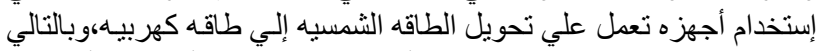

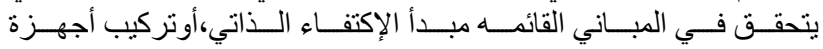
إستشعار بوجود مستخدمين في الفر اغات.

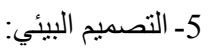

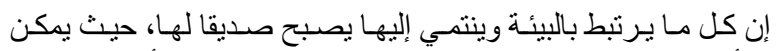

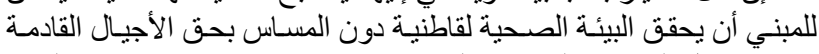

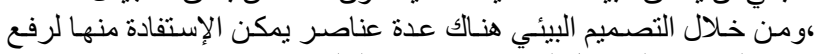

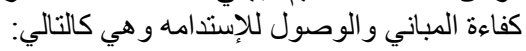

(1-1)فضل الطرق لتحسين العدر الإفتراضي للمبنى تتهثل في ما بلي: (2)

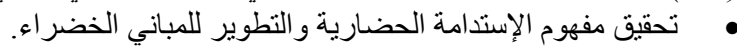

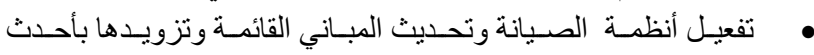
الآليات التكنولوجية.

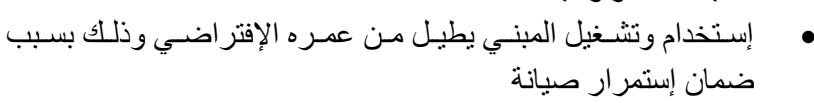

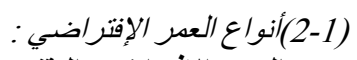

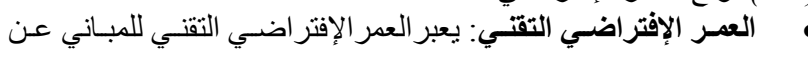

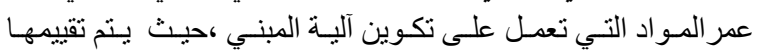

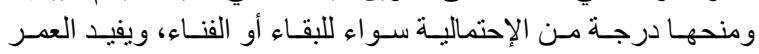

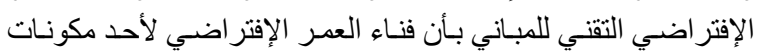

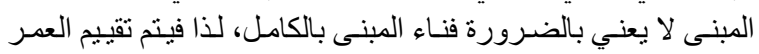

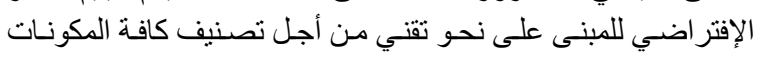

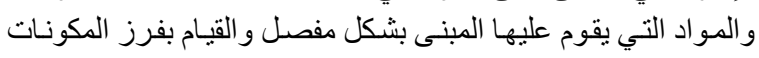

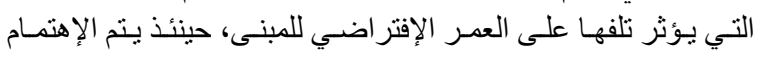

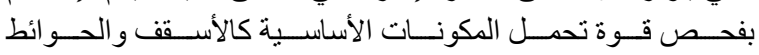

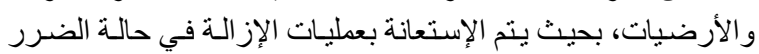

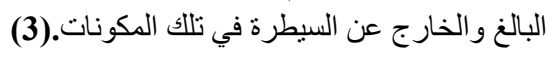

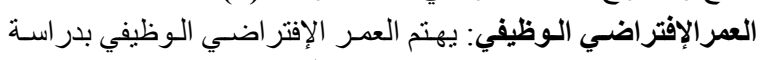

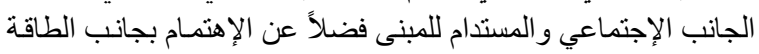

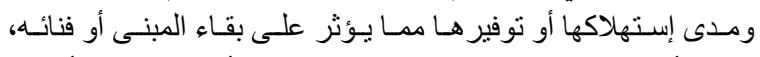

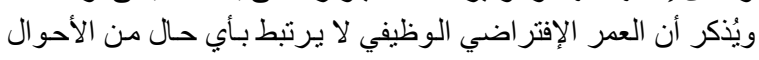

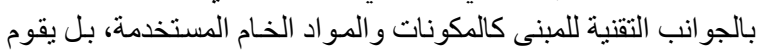

بالتركيز على عاملي الطاقة والإستدامة.

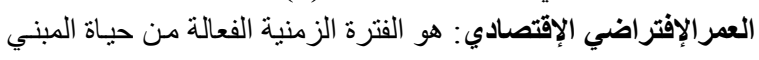

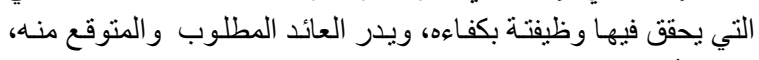

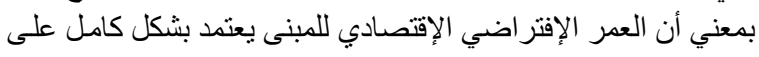

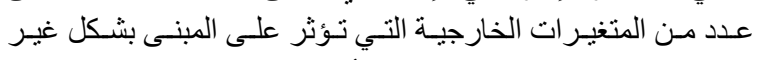

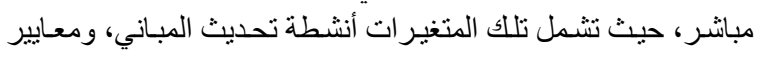

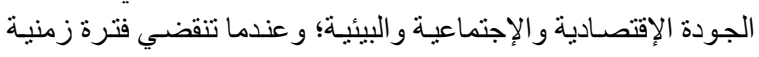
محددة على المبنى فإن القيمة السوقية لهذا المبنى في سوق الإنهائه الإستثمار

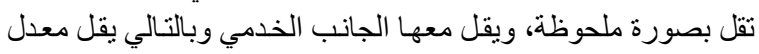

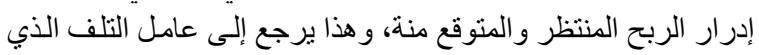

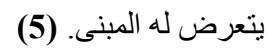

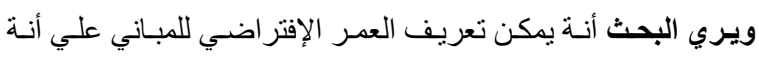

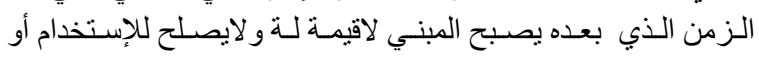

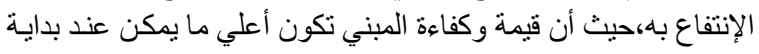

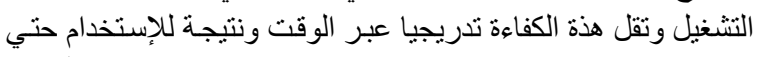

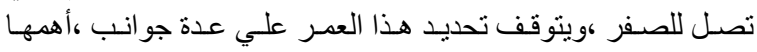

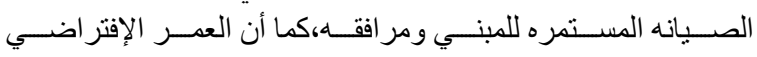

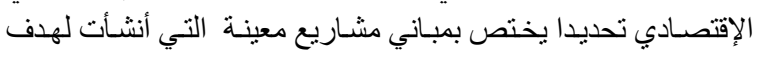
معين وهو إدرار الربح كالفنادق مثنلا.

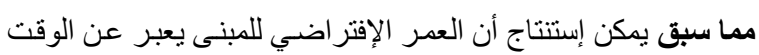

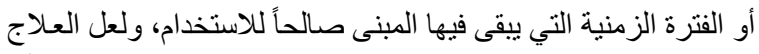

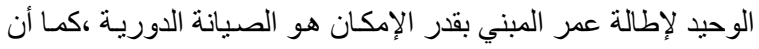
تشغيل المبني بإستمر ار يضمن إستمر ار صيانة أيضا. 2- إعادة تأهيل المباني القائمة :-

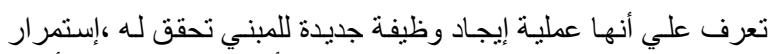

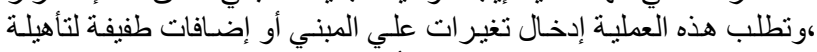

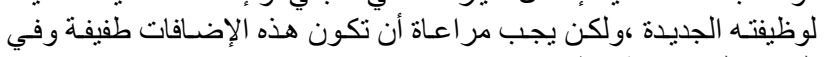

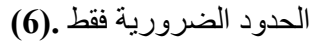

(7): (1-2) مستويات إعادة الثأهيل

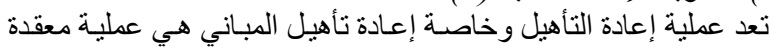

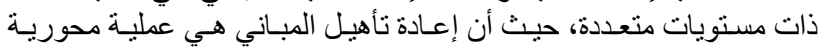
تشمل مجمو عة من المستويات ومنهات إدة مناء 


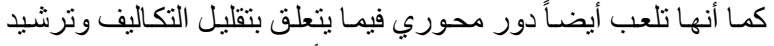

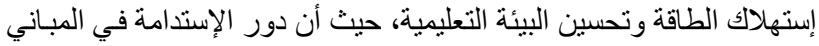
التعليمية ينطوي على ما يلي : النيفي

- تقليل التكاليف المادية و التشغيلية المتطلبة التئية لإنشاء المباني التعليمية.

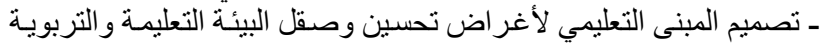

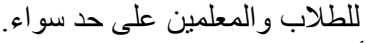

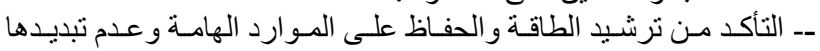
و الإسر اف فيها. تئان

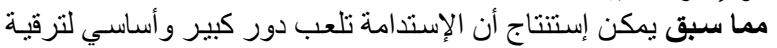

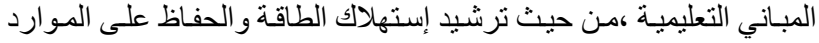

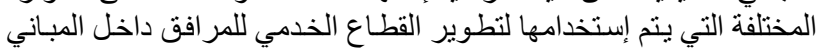

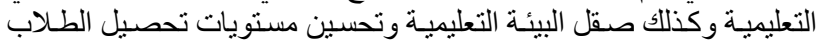
وكذلك تقليل التكاليف وتحسين الجانب الإقتصادي للمبنى التعليمي.

(3-6) معوقات تطبيق الإستدامة في المباني التعليمية:(13)

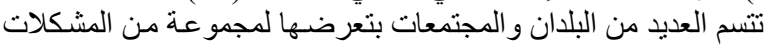

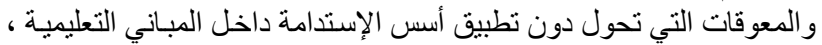

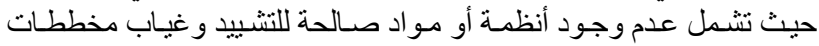

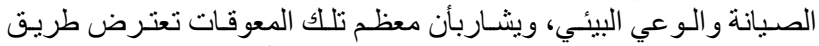

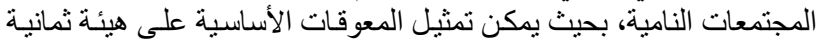
محاور رئيسية على النحو التالي: إنعدام الو عي الثقافي و التعليمي حيال أمثل الطرق للتعامل مـع المنـاخ البيئي المحيط. عدم وجود مايكفي من طرق إستخدام الطاقة ومواردهـا وكيفية ترشيد إستهلاكها،و إدارتها.

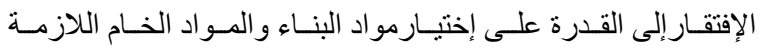
لعمليات التشييد.

عدم وجود أنظمـة إدارة مخلفـات مو ادالبنـاء ووضـع مخططسات لكيفيـة إعادة تدوير ها.

الإفتقار إلى القدرة والخبرة في إختيـار أفضل المو اقع الجغر افية لبنـاء

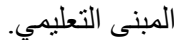
عدم تخطيط شبكات للنقل و المو اصـلات حول المبنى التعليمي لتوفير خيار ات مختلفة لعملية الإنتقال.

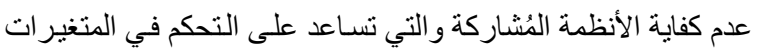
المناخية التي تحيط بالمبنى. غياب أعمال الصيانة الدورية و إعادة التأهيل و التقوية و الإصلاحات. ويري البحث:أنه بمكن أيضـا أن تتمثل معوقات تطبيق الإستدامة في

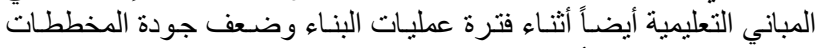

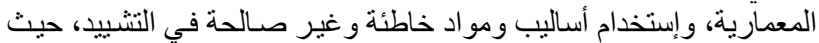
أن معوقات تطبيق الإستدامة في المباني التعليمية تتمثل أيضاً في ما يلي: الئي

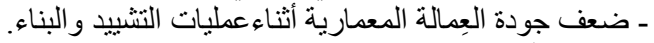

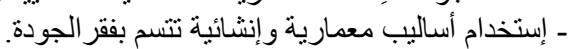

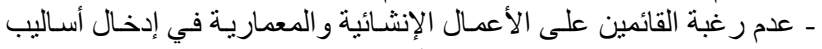

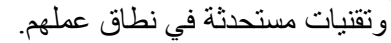
ـ قلة الكفاءة لدى المقاولين،و عدم تكو ينهم لقاعدة إستيعابية كافية إزاء أهداف

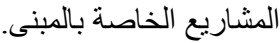

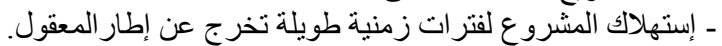

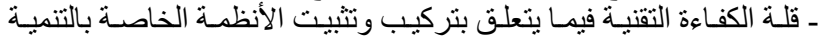

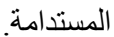

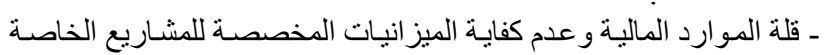
بتطبيق التنمية المستدامة في المباني التعليمية.

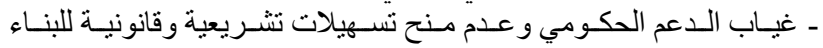
و النشييد.

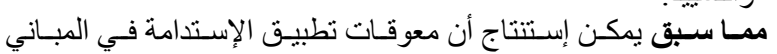

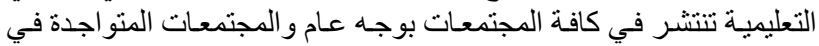

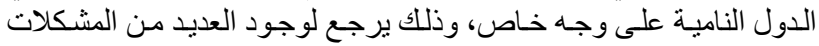

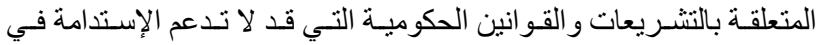

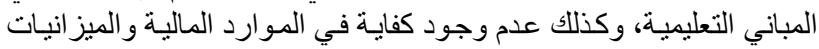

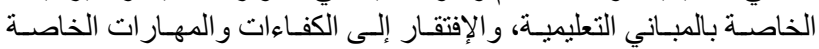

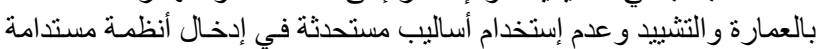

: (1-5) - الحلاف المبنـي

أولا- الحوائط:

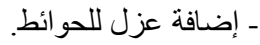

- ز - زراعة الحو ائط بالنباتات المتسلقة

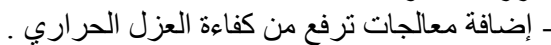
ـ ـ تغيير ألوان الحو ائط بالألو ان الفاتحه.

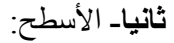

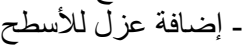

- ز زر اعة الأسطح وذللك بعد التأكد من عزلها جيدا قبل الزبل الزر اعة.

ـ طلاء الأسطح بطلاء عاكس .

- وضع خلايا كهروضوئية.

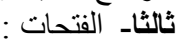

ـ تركيب مظلات أو أرفف عاكسة

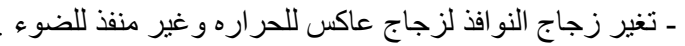

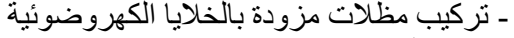

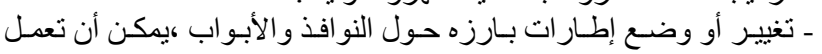
ككاسر ات للشمس.

(2-5) كفاءة إستخدام المياه:

أولا - الحفاظ علي المياه من خلال:

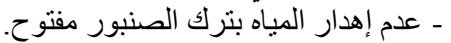
- إصلاح الصنابير التالفة.

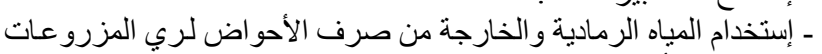

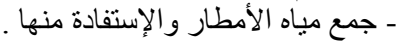

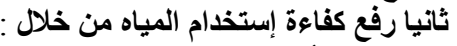

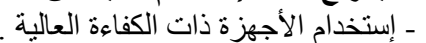

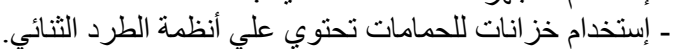

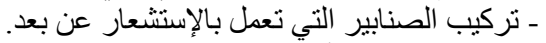

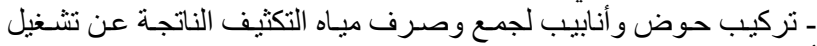

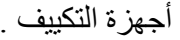

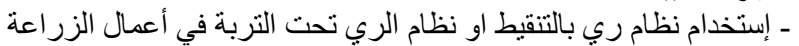

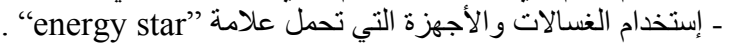

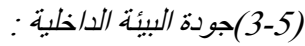

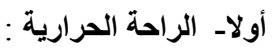

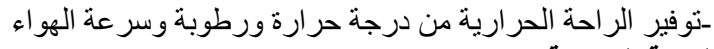

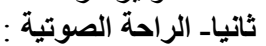

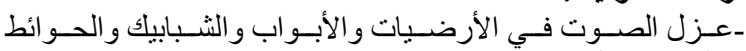

و الأسطح و الأسقف .

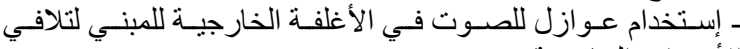

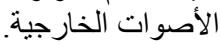

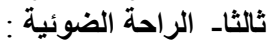

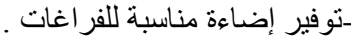

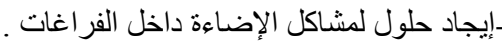

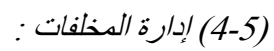

- إعادة التدوير - الحد من النفايات ـ تجنب إنتاج النفايات .

6- الإستدامة في المباني التعليمية:- (11)

(1-6) - (1-6) مفهوم الإستدامة:

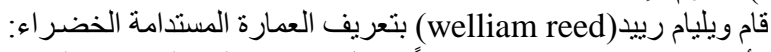

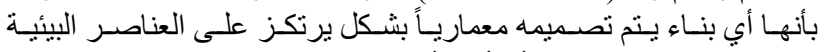

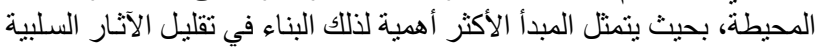

الناتجة عنه على البيئة المحيطة قدر الإمكان.

(2-6) دور الإستدامة في المباني التعليمية:(12)

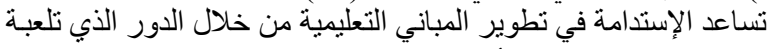

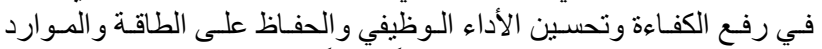

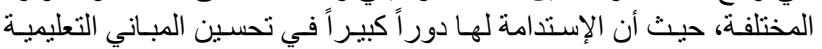

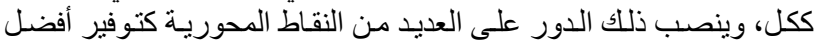
الظروف البيئية الممكنة داخل المبنى وخارجها. 
• (ثانيا) :دراسة حالة مبني كلية الهنسة بنين (المبني الرئيسي)-

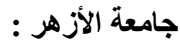

• نبذة عن المبني محل الدراسهة:

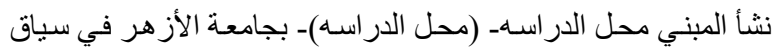

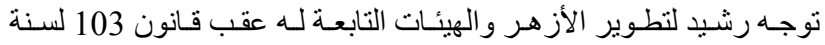

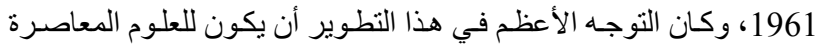

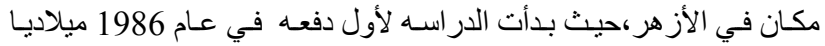

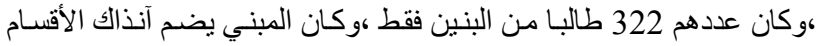

(قسم الهندسه المعماريه وقسمي التخطيط العمر اني و البترول و التعدين

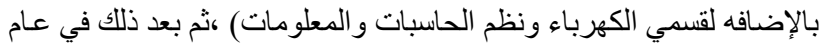

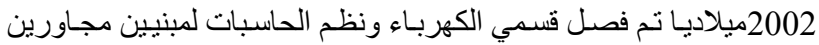

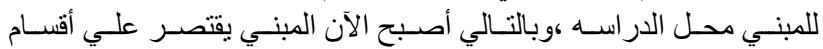
(العماره و التخطيط العمر اني و البترول و التعدين ) ).

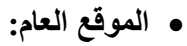
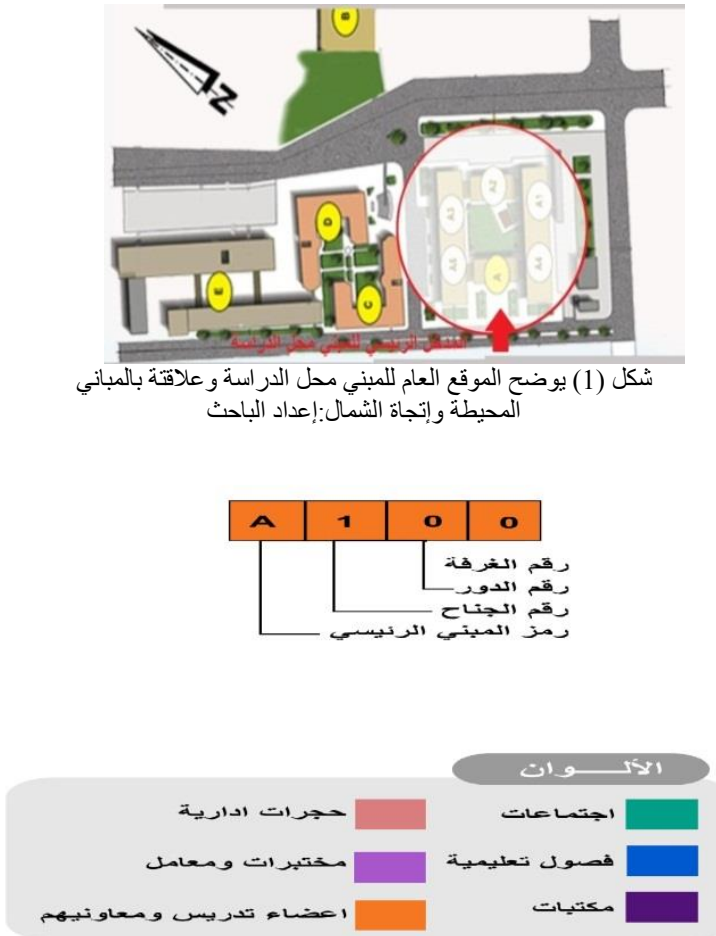

شكل(2) يوضح المفاتيح والرموز للمساقط الأفقية التالية:إعداد الباحث

• الوصف المعماري: يحتوي المبني الرئيسي لكلية الهندسـة بنين علي 5 مداخل رئيسية بالدور

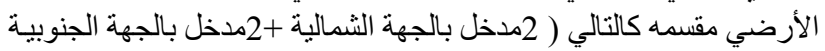

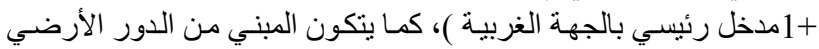

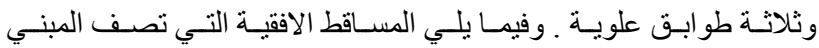

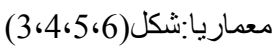
يحتوي المبني الرئيسي لكلبـة الهندسـة بنين علي 5 مداخل رئيسية بالدور

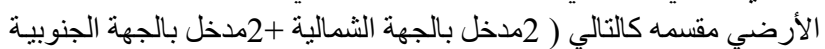

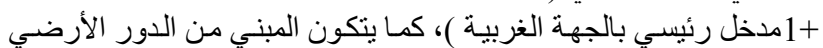

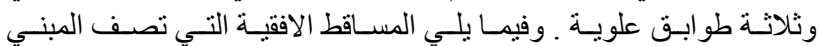
معماريا:
حديثة، وهو ما يرجع لقلة المعلومات والخبرات الخاصـة بالتنمية المستـامة بشكل عام.

(4-6) أهمية عملية إعادة التأهيل المستدام للمباني التعليمية:(14)

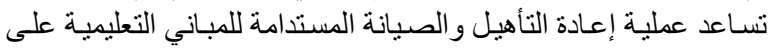

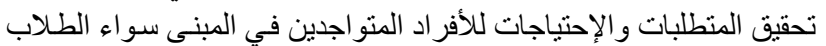

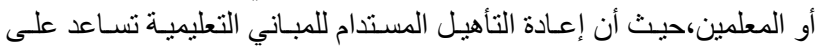

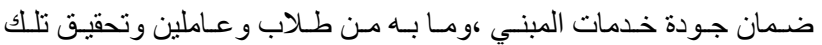

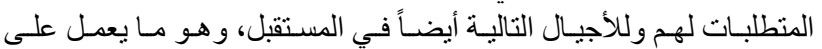

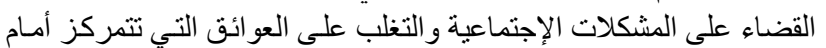

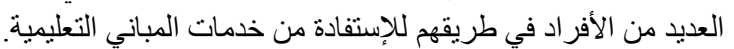

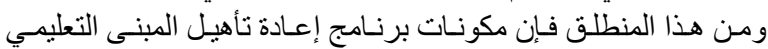

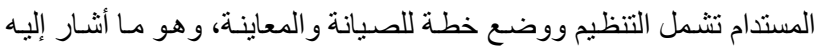
"بار وكورس ودونبار " (Barr, Cross, \& Dunbar, 2017, p. 12) حينما أكد على أنه يمكن تحديد مكونات بر امج إعادة التأهيل المستدام للمباني

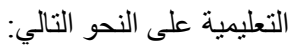
• التنظيم: لاشتك أن الهيكل التنظيمي الأساسي لبرنـامج إعـادة التأهيل

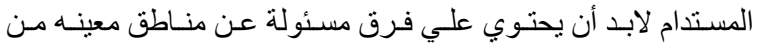

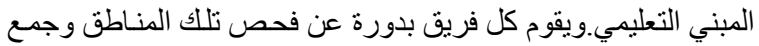

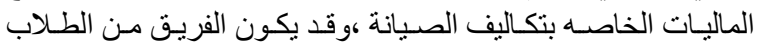

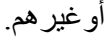
خطه الصيانة: ترتكزخطه الصيانة علي وضع جدول زمني للمعاينات

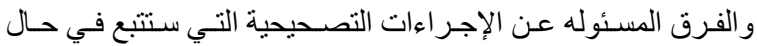

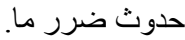
المعاينة:عبارة عن التقييم النهائي بعد إستكمال أعمال إعادة التأهيل

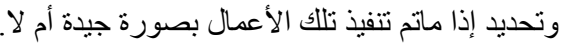

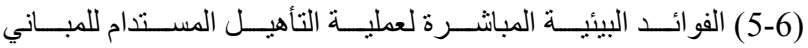
التعليمية:(15) (15)

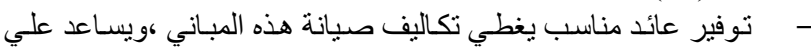

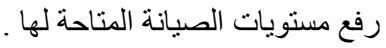
إيجاد نوع من الإشر اف الدائم علي هذه المباني عن طريق الهن مستخدميها

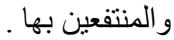

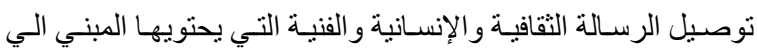

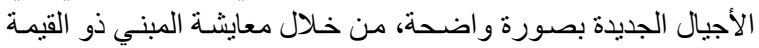

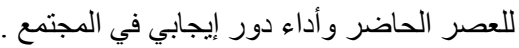

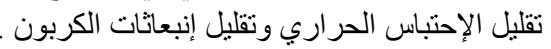
تحسين جودة البيئة الداخلية . تلارئ

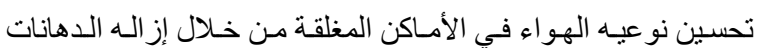

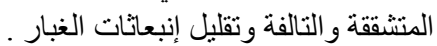

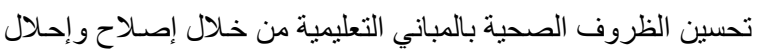

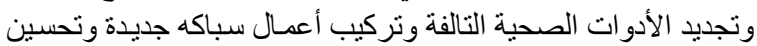

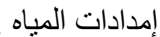

تقليل مخـاطر الإنزلاق علـي الأرض من خـلال إستبدال الأرضيات التالفة و الأرصفة و الدرجي.

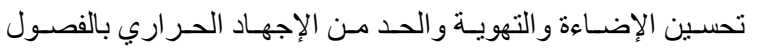
و القاعات الدر اسية. ممـا سـبق يمكن إستنتاج أن لإعـادة التأهيل المستـدام للمبـاني التعليميـة

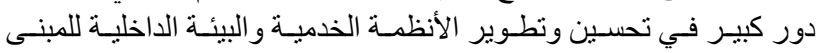

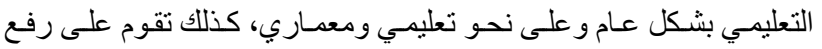

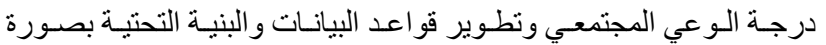

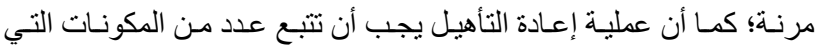

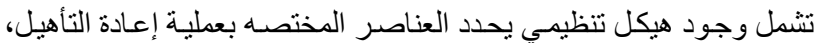

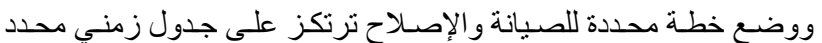

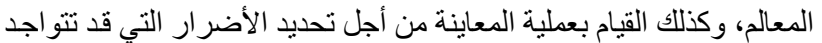
في المبنى بعد عملية إعادة التأهيل. 


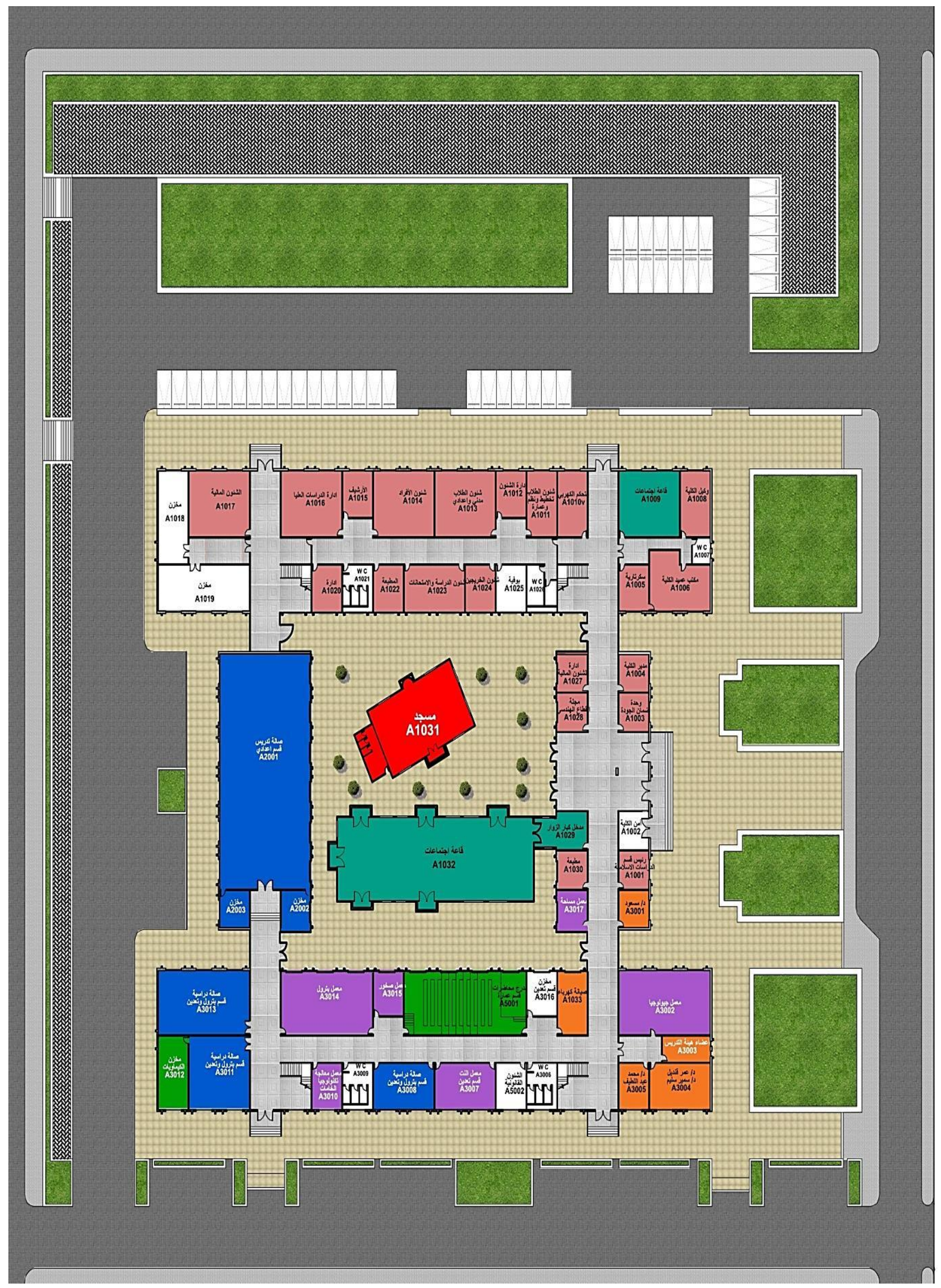




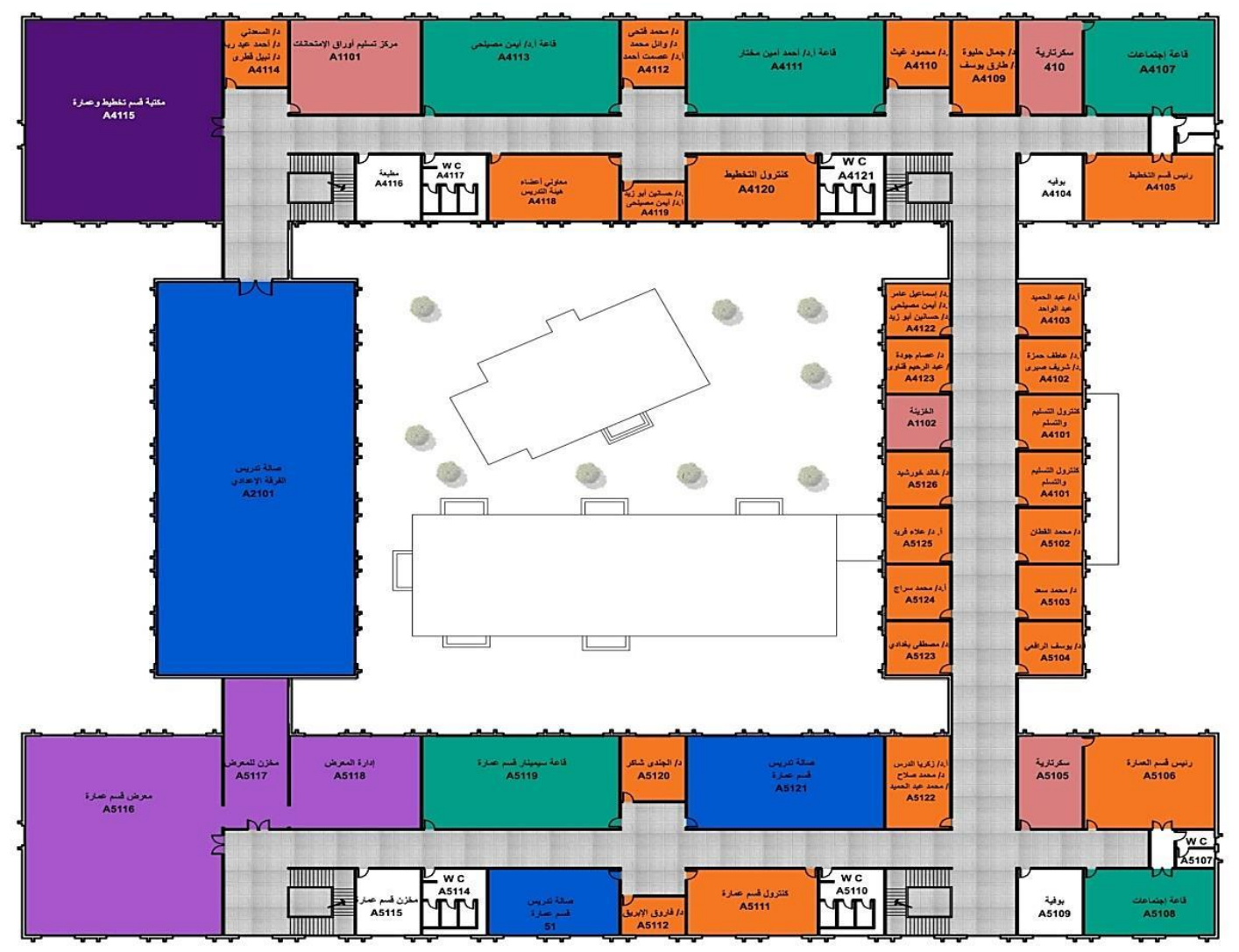

شكل(4) يوضح المسقط الافقي للدور الاول علوي: إعداد الباحث

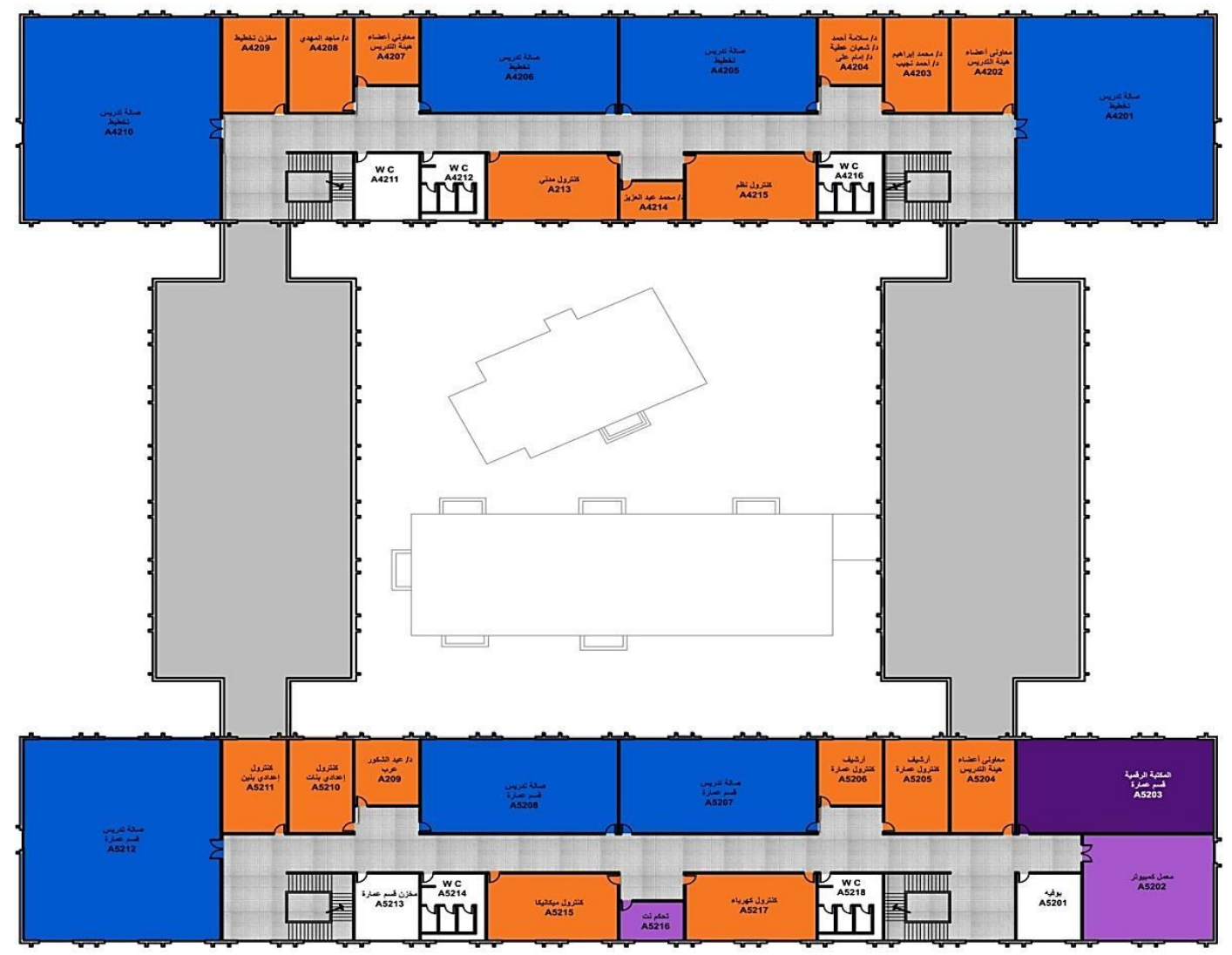

شكل(5) يوضح المسقط الافقي للاور الثاني علوي: إعداد الباحث 


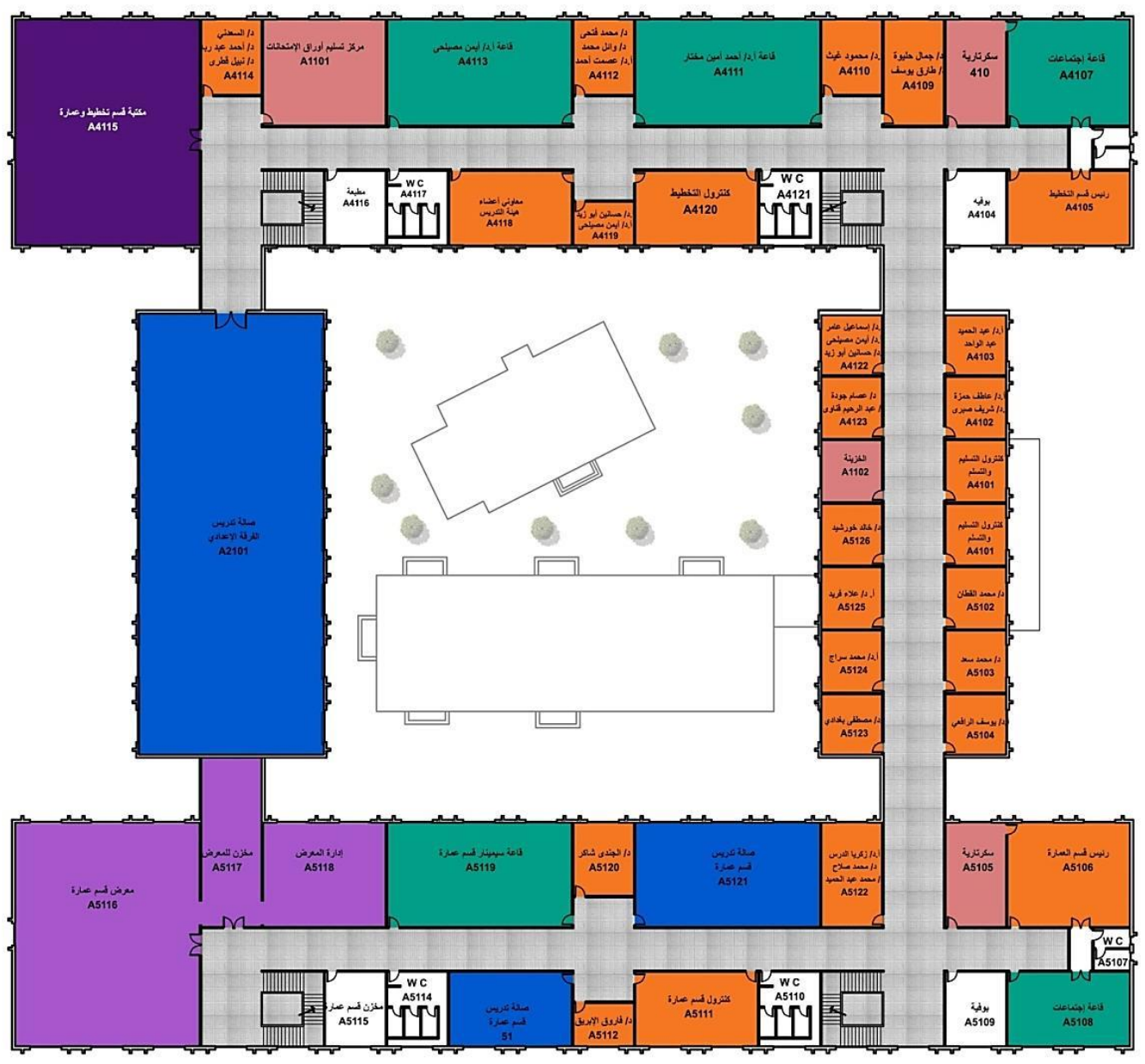

شكل(6) يوضح المسقط الافقي للاور الثالث علوي: إعداد الباحث

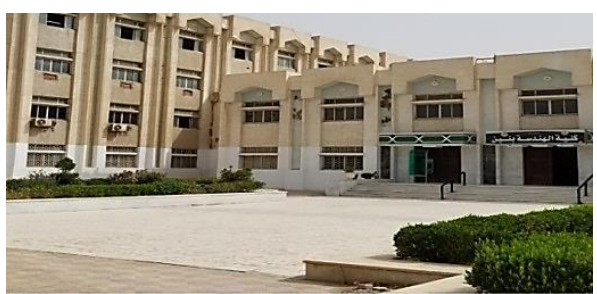

شكل (8) :يوضح ساحة المخل وخلو ها من التظليل تصوير : الباحث

• منهج در/سةة/الحالة: تتم در استة حالة المبني محل الدراسة اسة علي ثلاثه محاور.

المحور الأول: محور إعادة تأهيل المبني وتفقد أحو الة من مشاكل و عيوب.

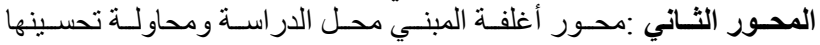

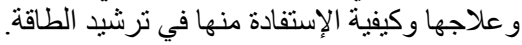
مع مر اعاة النو احي الإقتصادية.

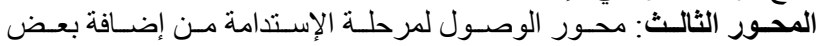

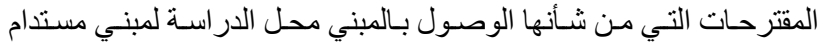
بنسبه كبيرة المحور الرابع: در اسـة الطاقة المستهلكة في المبني محل الدراسـة وحلول تقليلها.

المحور الاول :محور إعاده تأهيل وصيانة المبني محل الدراسة

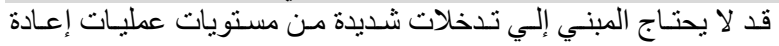

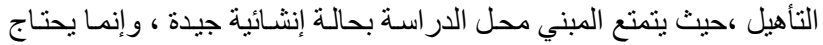

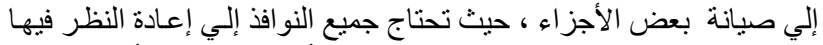

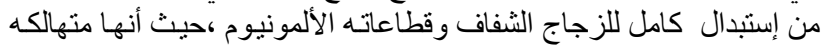

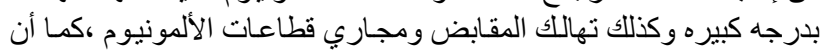

• أبرز المشاكل التصديمبة الموجود بالعبني من وجهة نظر البحث:

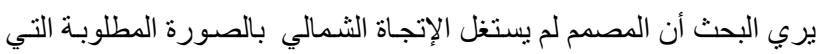

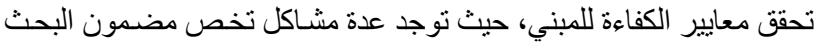

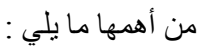

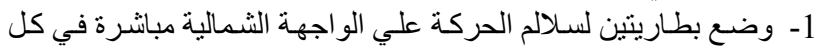

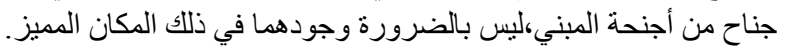

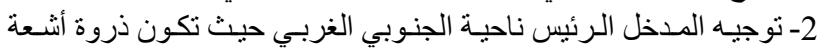

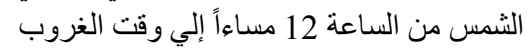

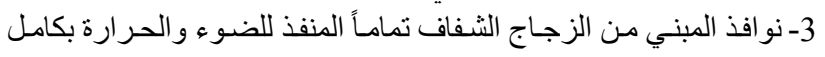

$$
\text { درجاتهما. - ن نوان. }
$$

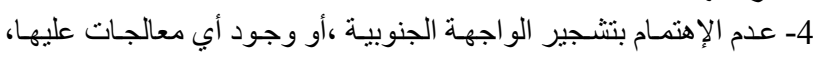

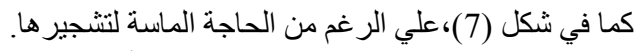

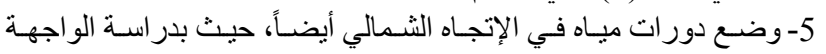
الشمالية تبين للباحث أن دورات التيات الاتباه المياه

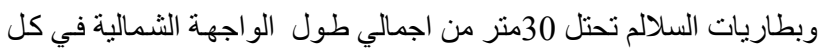

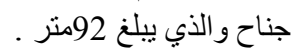

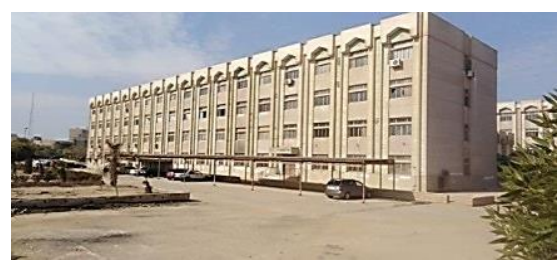

شكل (7) يوضح الو اجهه الجنوبيه وخلو ها من أية معالجات تصوير :الباحث 
• أغلفة المبني محل الدراسة والأحمال الحر اريه المؤثره عليها:

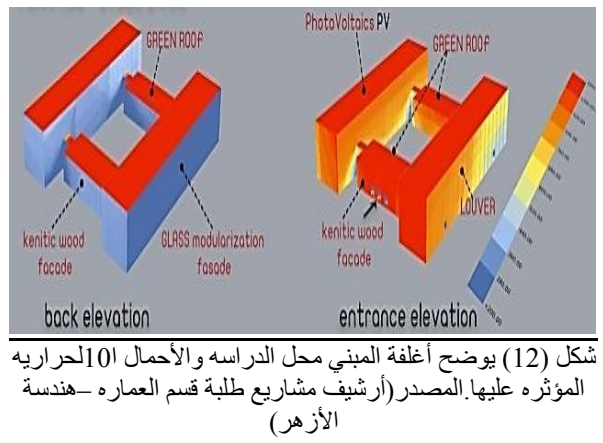

• در اسة تطبيق معالجات العناصر المكونه للغـلاف الخـارجي للمبني محل

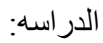

تتــاول هذه الدر اسـهـ التحليليـه أثرتطبيـق معالجـات العناصـر الرئيسـيه

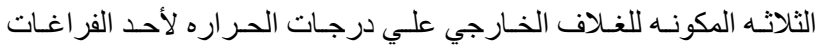

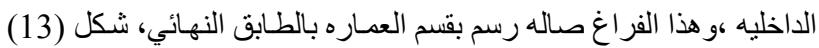

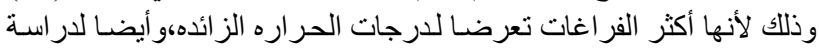

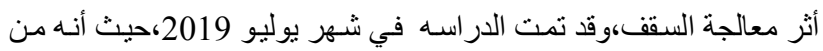

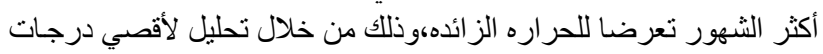

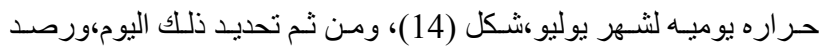

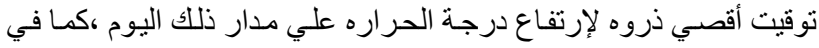

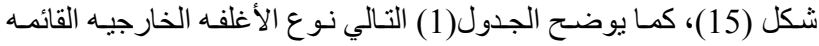
للمبني محل الدر اسه ومعدلات الإنتقالات الحر اريه بها.

جدول (1)

يوضح الأغلفه الخارجيه للمبني القائم محل الدراسه ومعدلات الإتنقاليه الحراريه

(16) بها
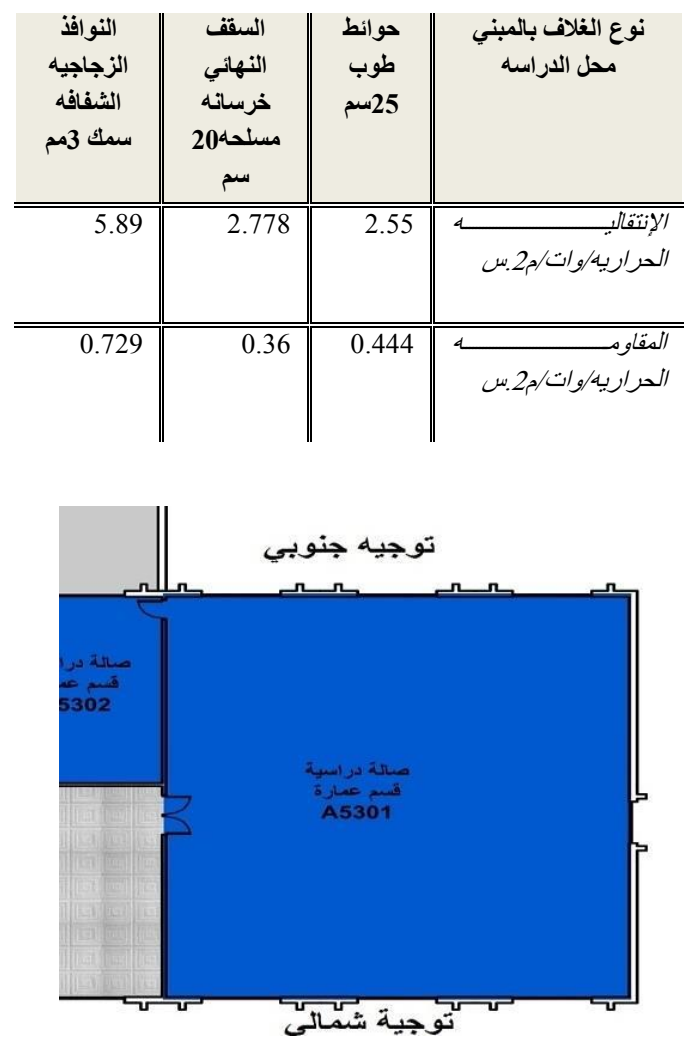

شكل (13) يوضح مسقط أفقي لصالة الرسم محل الدراسه بالطابق النهائي إعداد الباحث البثاب

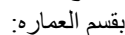

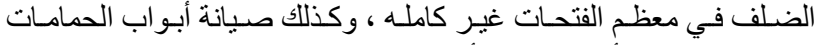

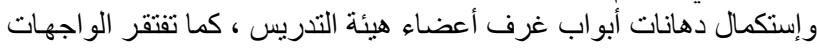

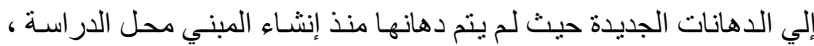

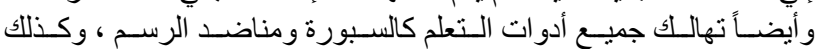

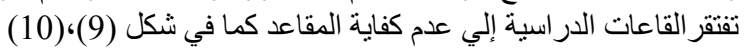
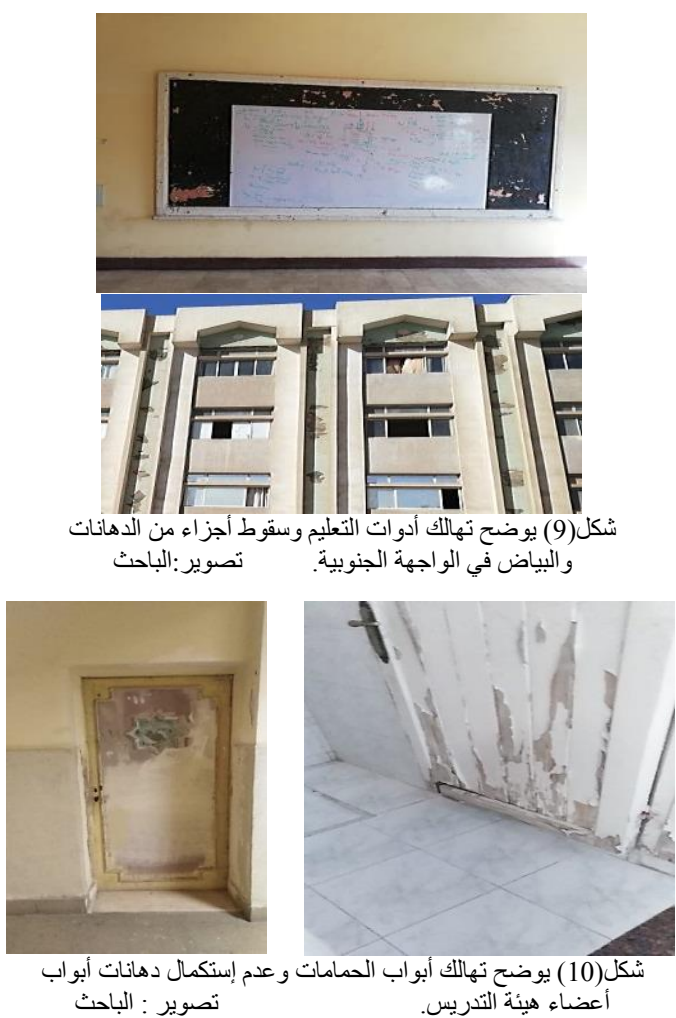

المحور الثاني:رفع كفاءة المبني محل الاراسه والا كفاءه البيئه الحراريه:

• الخصـائص البيئيـه للمنــاخ المحبط بأغلفة المبنـي محل الدر اسـهـ(مدينـة

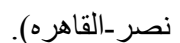

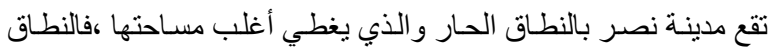

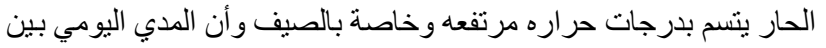

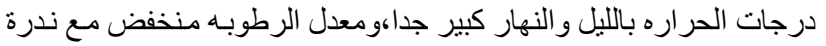

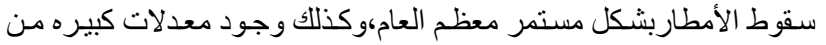

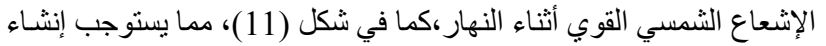

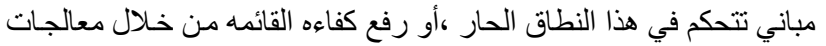

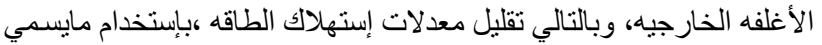
بمعايير التصميم السالبة.

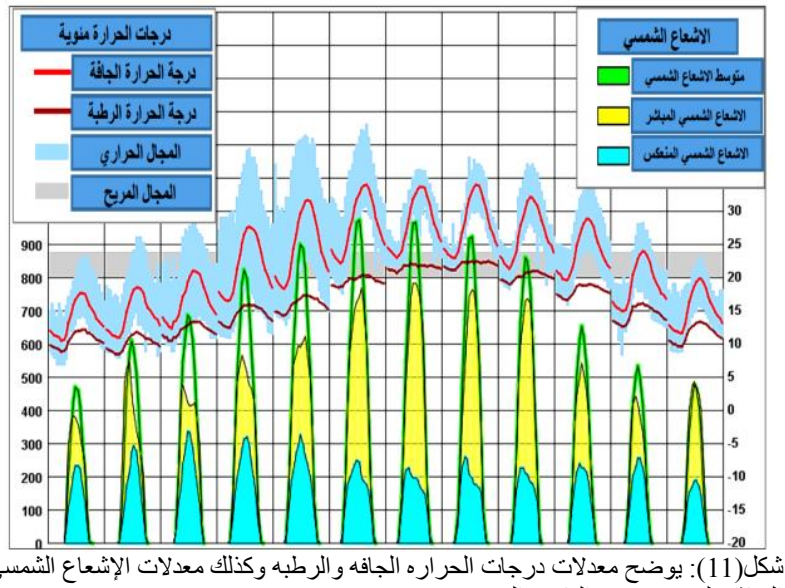

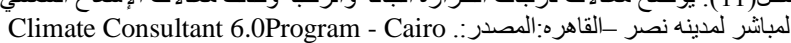
Weather Data 
زر عها فوق السقف النهائي بعد طلاءه بالمو اد العاكسه ،مما يسـهم في تظليل

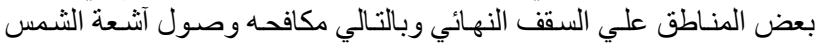

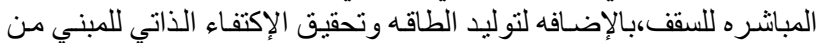

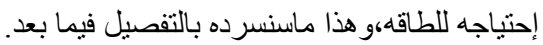

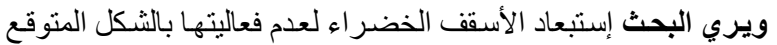

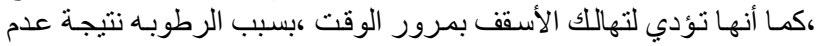

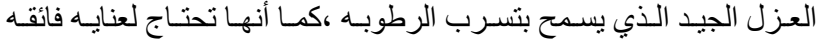

ومتابعه مستمره.

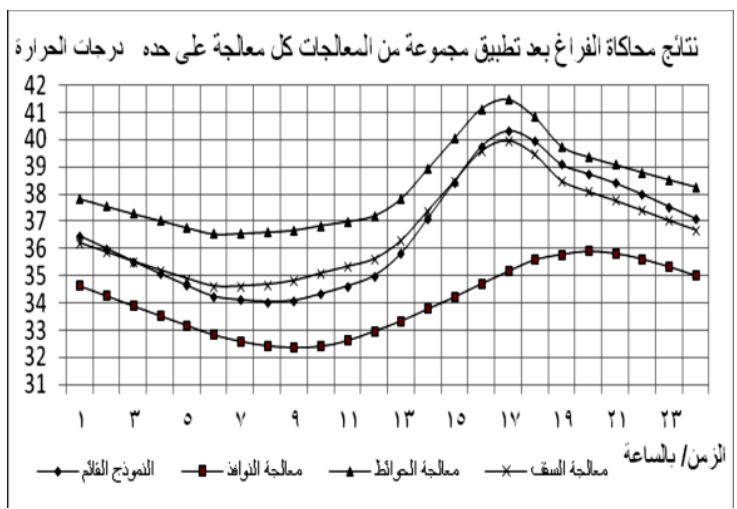

شكل (16) يوضح نتائج محاكاة الفر اغ بعد تطبيق مجمو عه من المعالجات كل معالجه

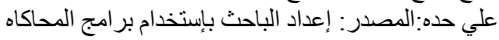

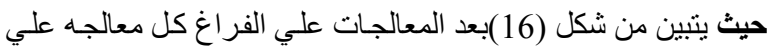

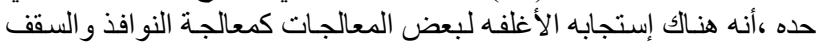

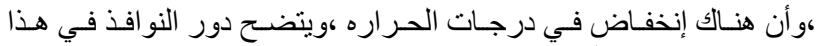

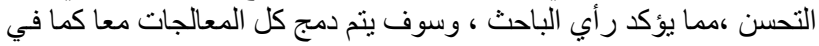

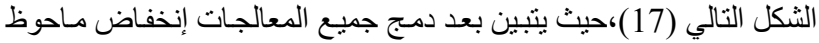

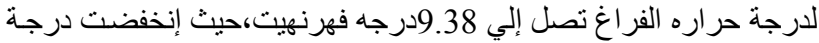
الحر اره من هراره 40.33إلي 30.95درجه فهرنهيت.

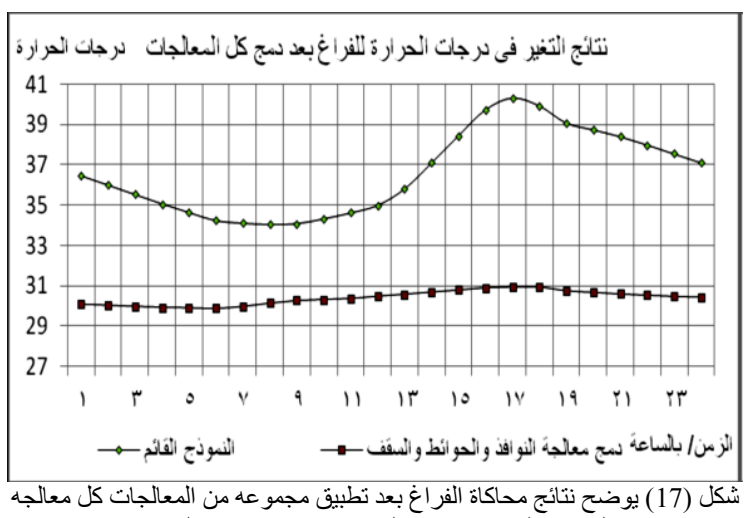
علي حده:المصدر : إعداد الباحث بإستخدام بر امج المحاكاه

معدلات وأحمال التبريد الإفتر اضية للفر اغ السابق محل الدر اسه:

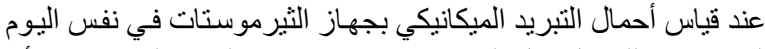

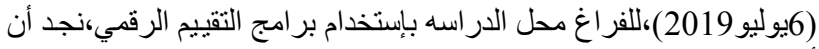

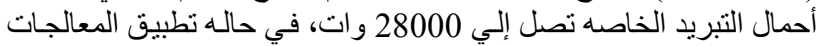

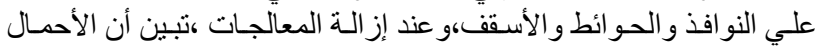

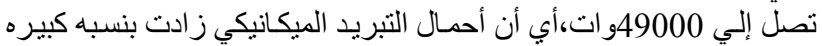

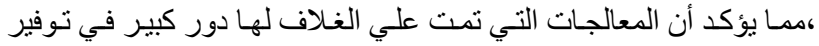

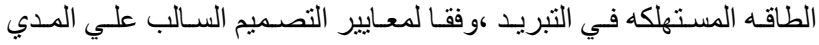

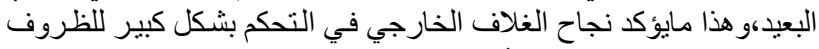

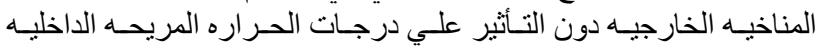

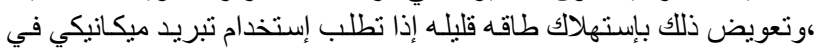

بعض الأيام الحاره من العام،كما في شكل (18)

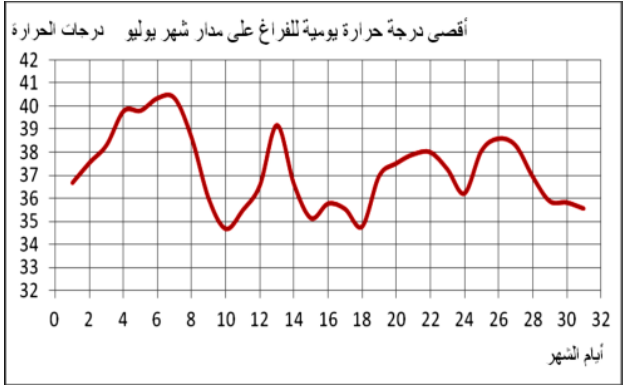

شكل (14) يوضح أقصي درجة حراره يوميه لثهر يوليو للفراغ باستخدام بر امج المحاكاه

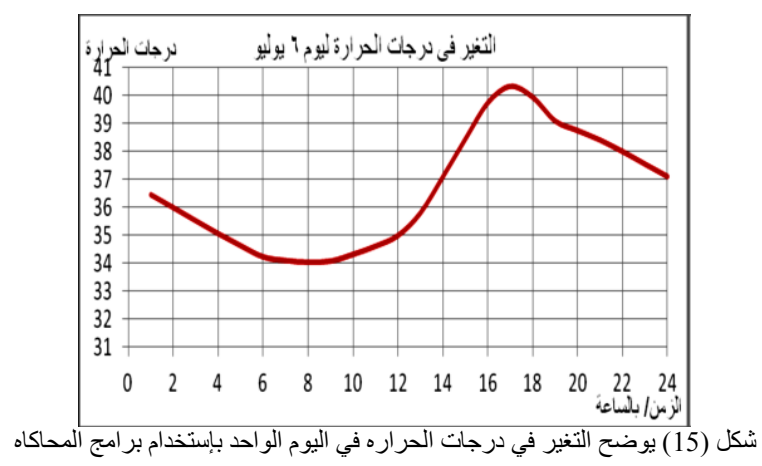

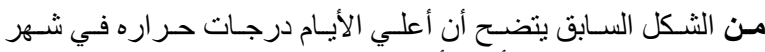

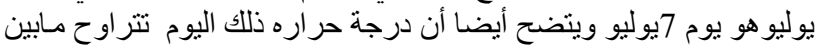

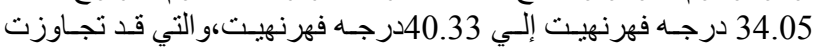

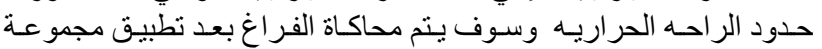

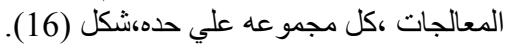
أولا معالجة الحو/يط: لاشك أن الهدف من معالجة الحوائط هو تأخير زمن توصيل مـادة البناء

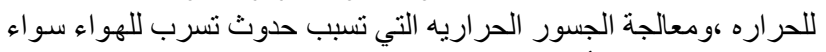

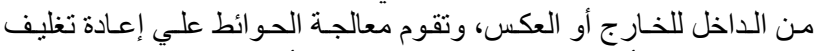

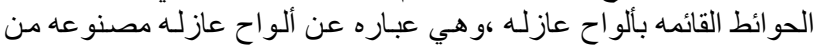

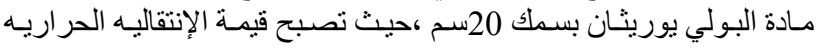

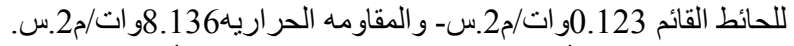

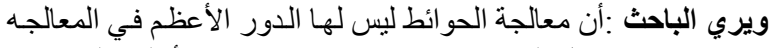

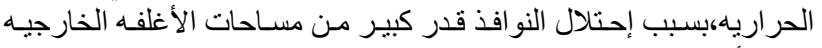

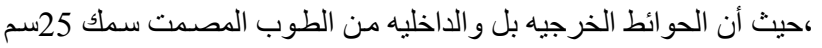

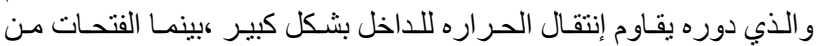

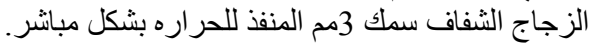

ثانيا معالجة النوافذ:

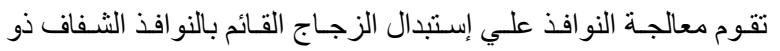

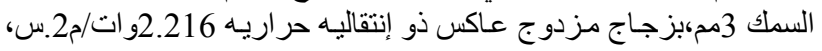

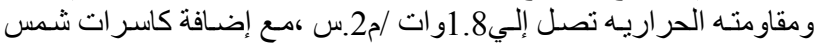

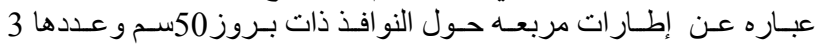

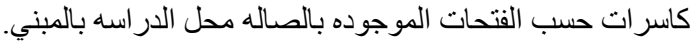

ثالثا معالجة الأسقف:

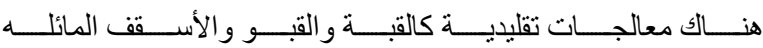

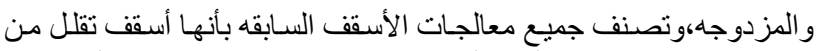

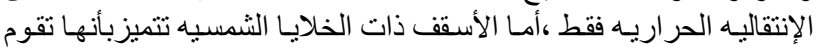

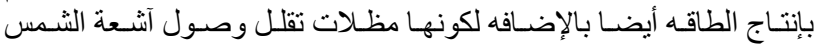

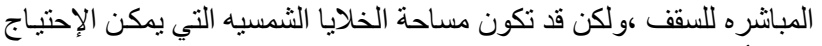

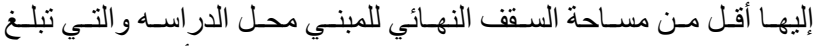

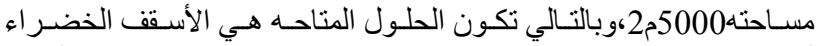

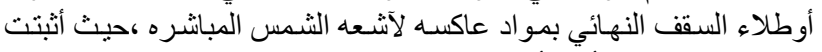

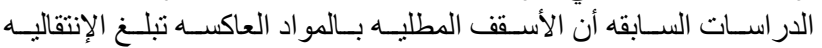

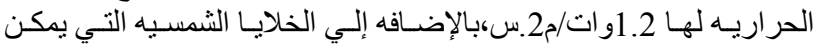




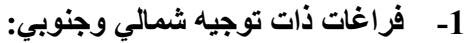

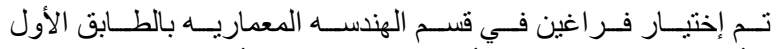

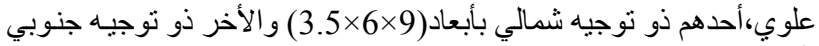

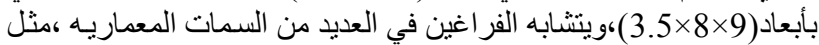

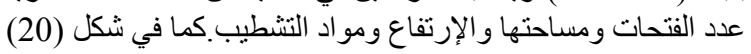

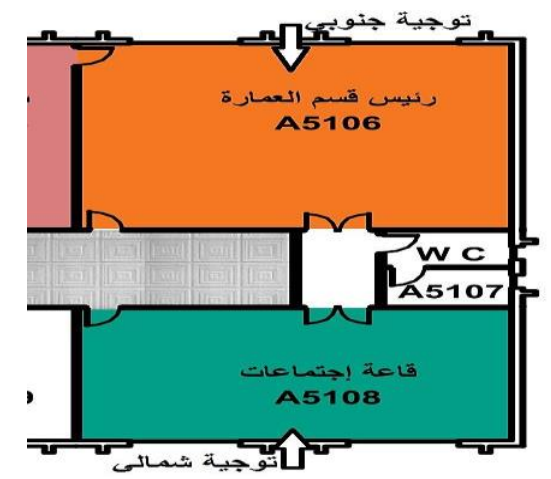

شكل(20)يوضح المسقط الأفقي لفر اغين متقابلتين أحدهما ذو توجيه شمالي والأخر ذو توجيه جنوبي:المصدر إعداد الباحث الهن

• ت تحليل نتائج القباسات:

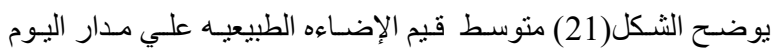

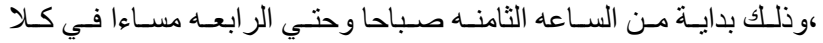

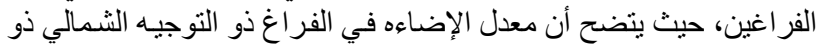

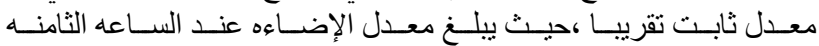

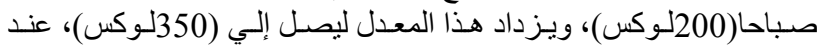

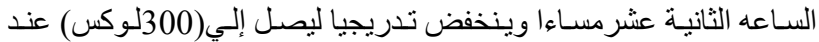

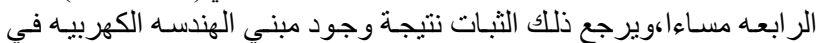

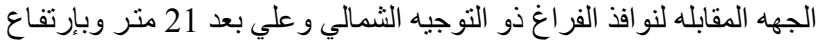

(17). 19

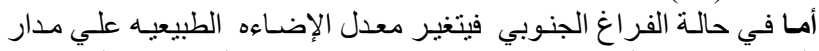

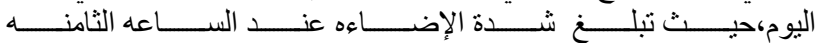

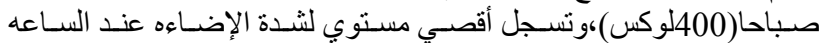

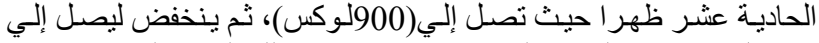

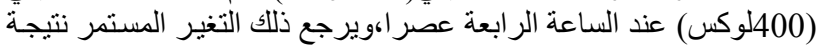

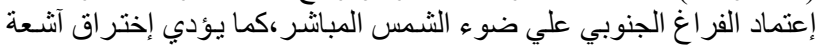

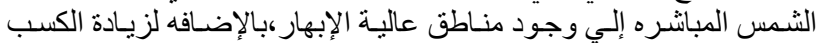

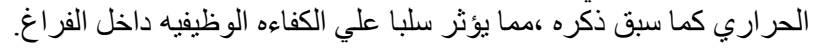

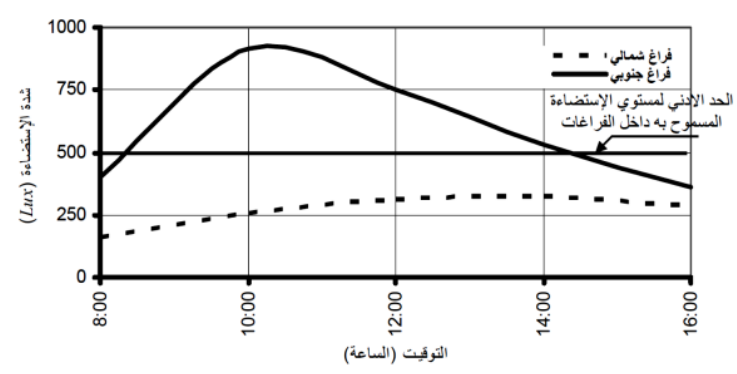

شكل(21)يوضح متوسط شدة الإضاءه داخل الفراغين الثمالي و الجنوبي خلال

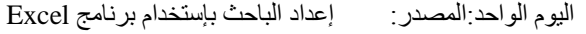

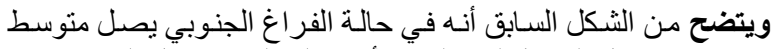

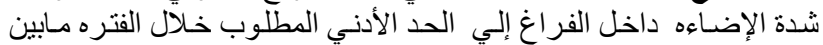

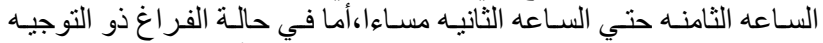

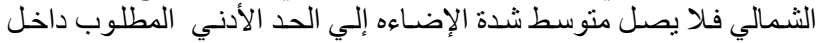

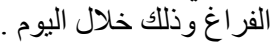

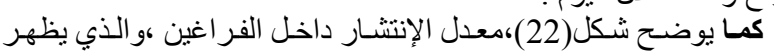

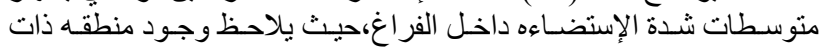

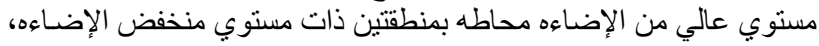

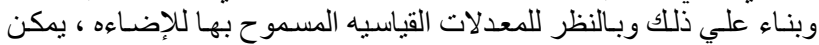

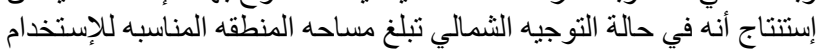
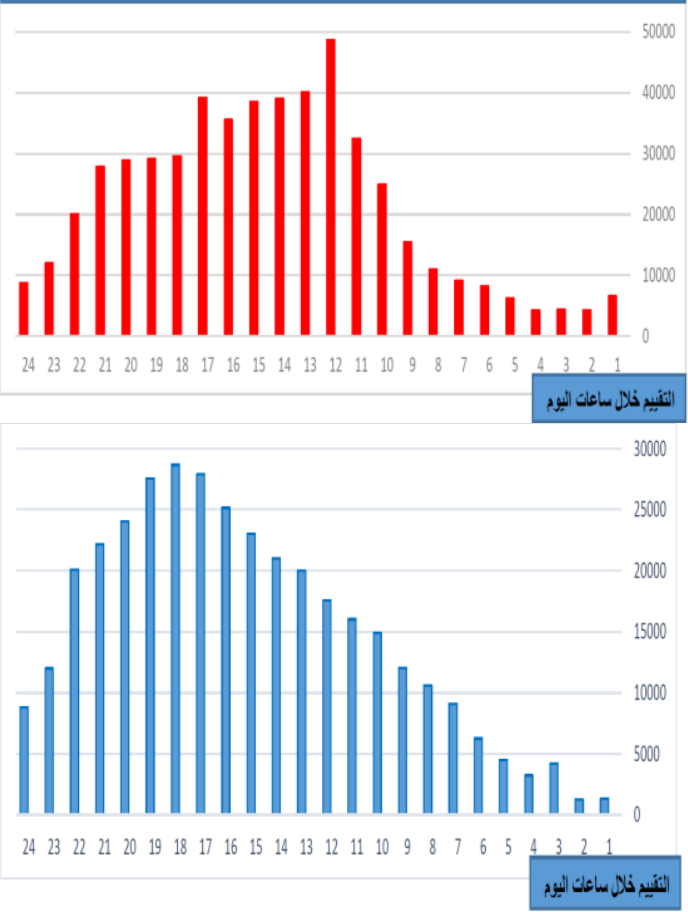

شكل (18) يوضح معدلات التبريد الميكانيكي قبل وبعد تطبيق المعالجات علي

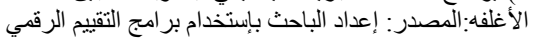

$$
\text { • نتائج كفاءه البيئه الحر اريه للمبني محل الدر اسه: }
$$

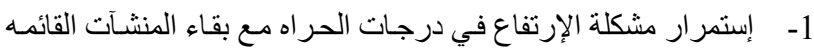

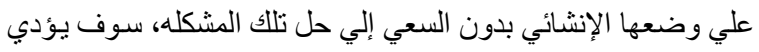

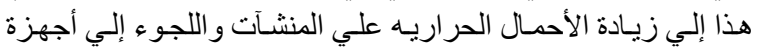

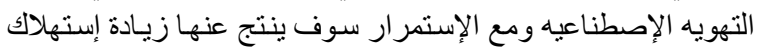
الطاقه . 2- إتضح من البحث مدي أهمية تقنيات التبريد السـالب ،و التي تلعب دور

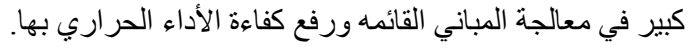
• توصيات خاصه بكفاءة البيئه الحر اريه للمبني محل الدر اسه:

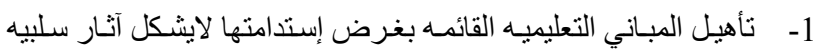

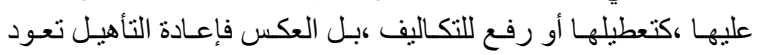

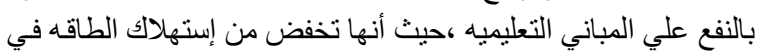

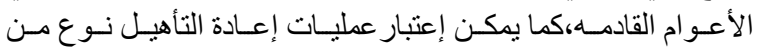
الصيانه الصبفيه.

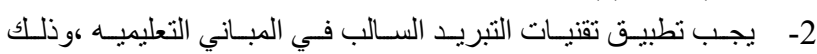

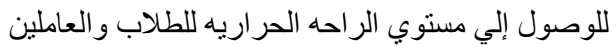

• ت نانيا كفاءه البيئه الضوئيه:

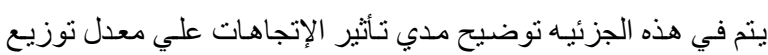

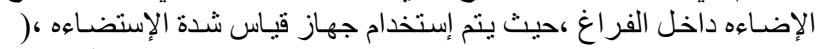

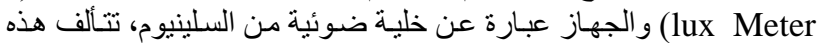

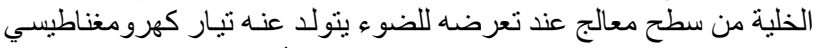

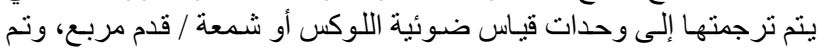

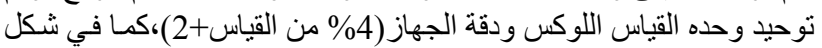

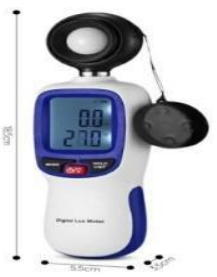

شكل (19) يوضح نوع الجهاز المستخدم في قياس شدة الإضاءه.المصدر:تصوير الباحث 
• تحليل نتائج القياسات:

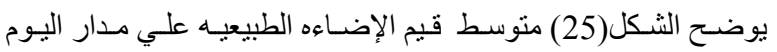

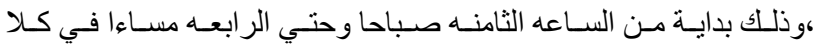

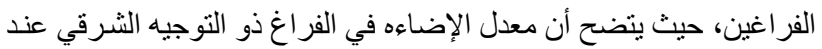

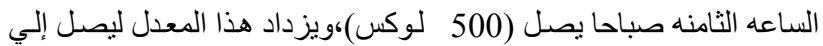

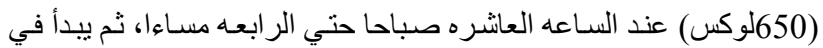

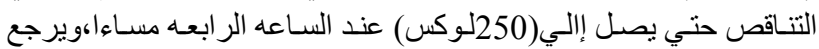

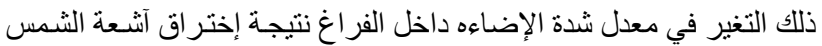

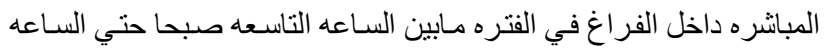

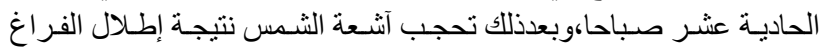

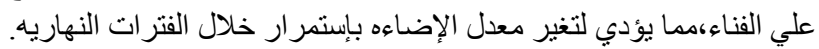

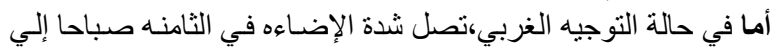

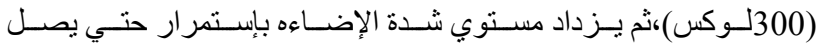

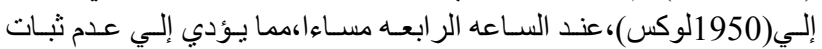

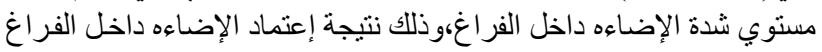

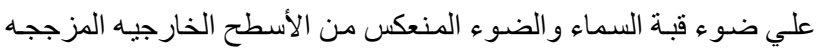

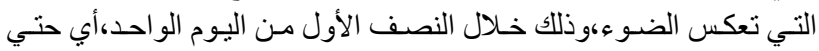

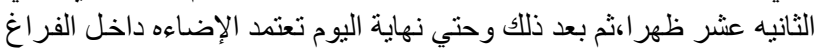

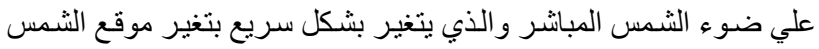
بقبة السماء

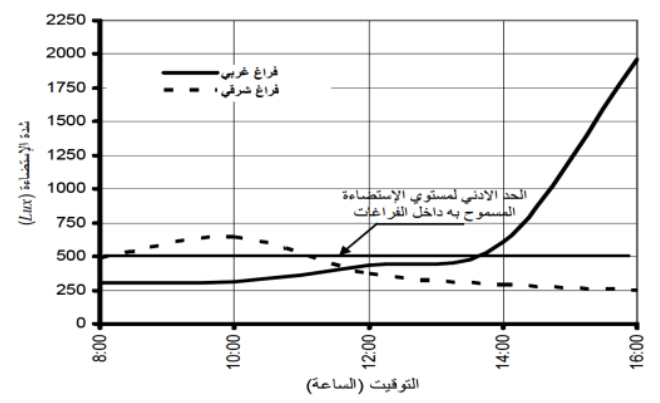

شكل(25)يوضح متوسط شدة الإضاءه داخل الفراغين الثرقي والغربي:المصدر : إعداد الباحث

كمـا يوضـح الثـكل (26) التالي،معدل الإنتشــار للضـو ءالطبيعي داخل

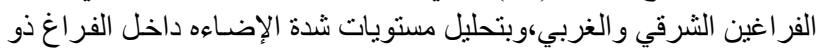

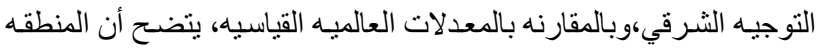

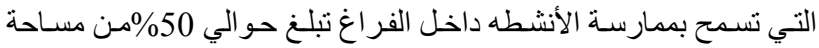

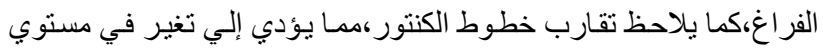

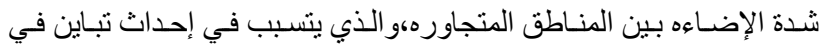
مستوي شدةالإضاءه داخل الفراغ. الإن.

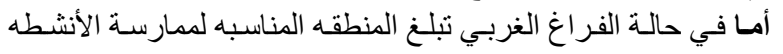

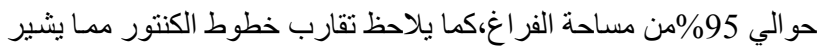
إلي حدوث تباين أيضا داخل الفراغ.

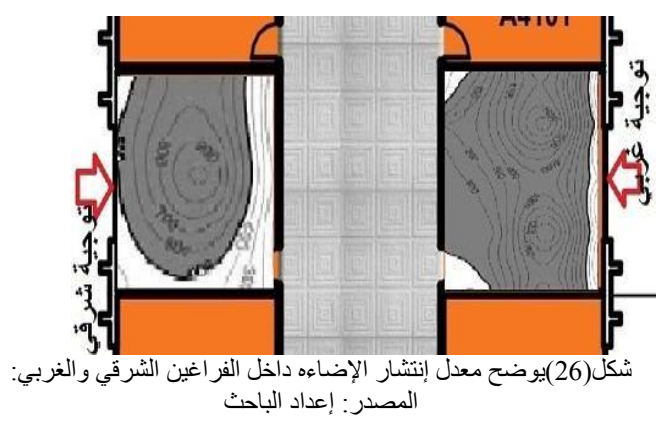

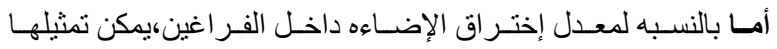

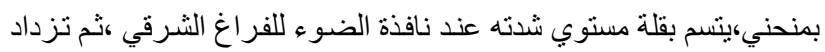

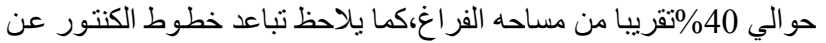

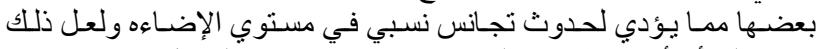

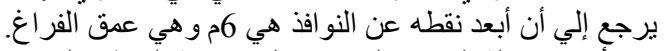

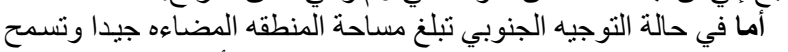

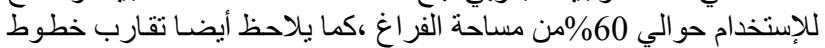

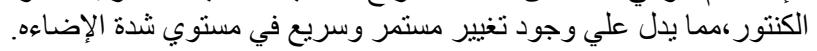

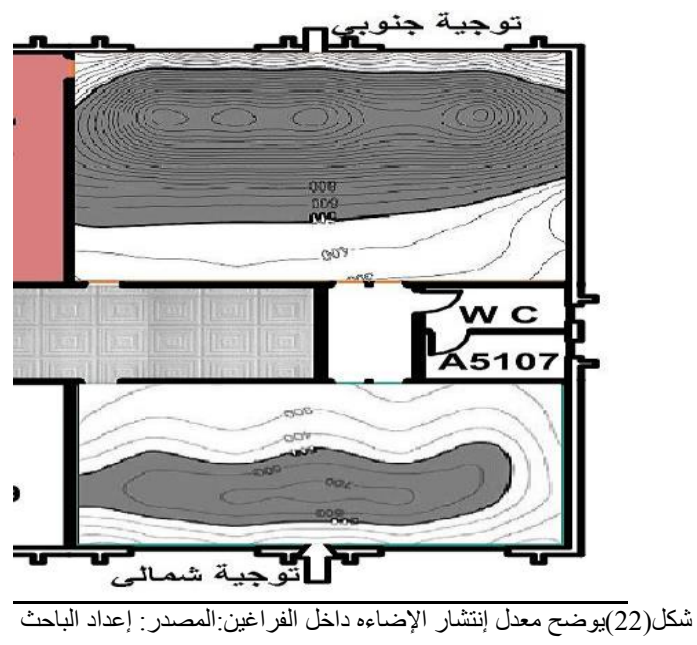

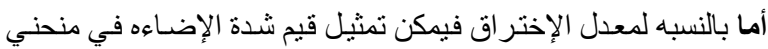

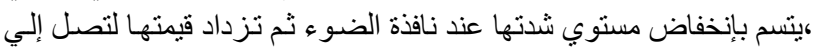

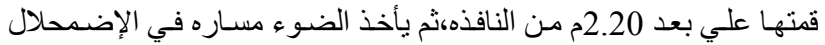

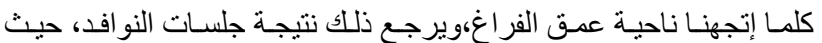
تعمل كمصده للضو ع،كما في شكل (23)

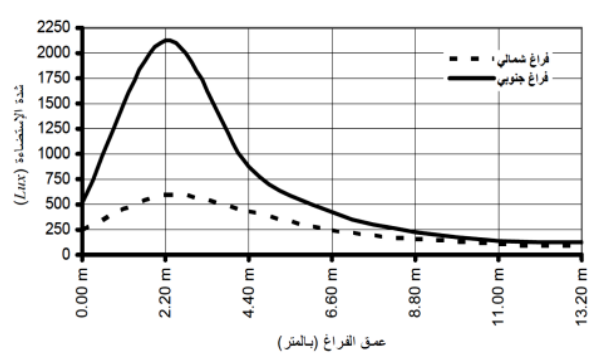

ثكل (23)يوضح منوسط إختراق الإضاءه داخل الفر اغين الثمالي و الجنوبي خلال

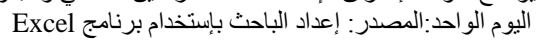

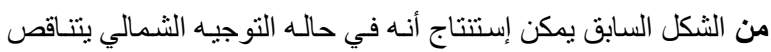

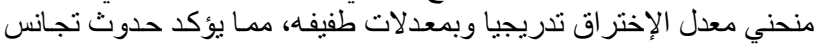

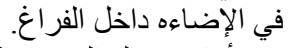

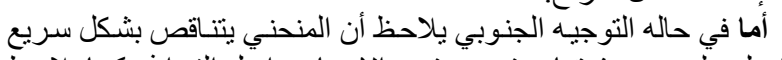

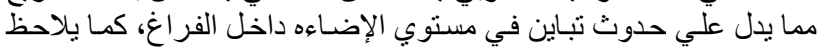

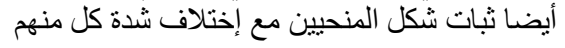
2- فراغات ذات توجيه شرقي وغربي:

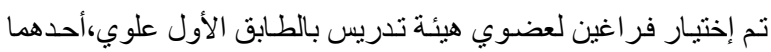

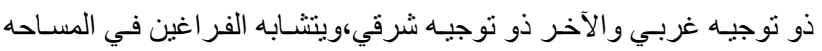

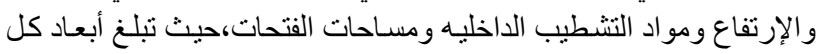
فر اغ منهما (5×5×5 (3.5)بالمتر ،كما في شكل (24)

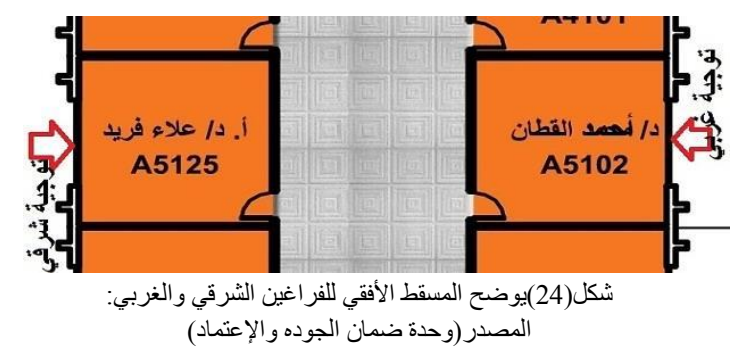


3- الفراغ ذو التوجيه الثرقي يزداد فيه مستوي الإضاءه في بدايه اليوم ثم

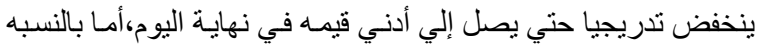

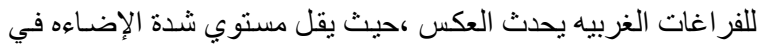

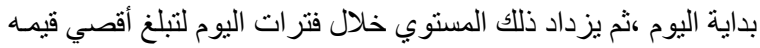

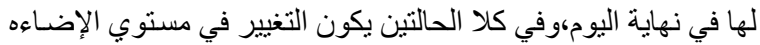

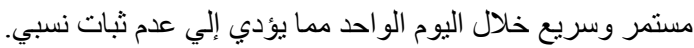

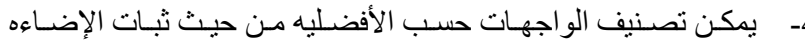

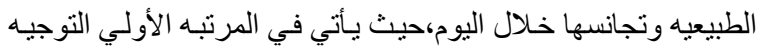

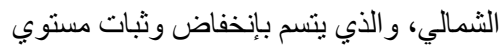

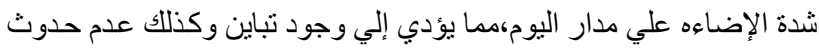

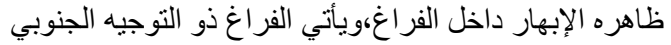

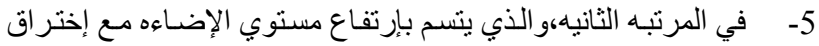

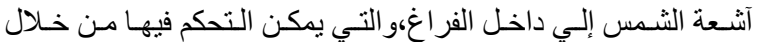

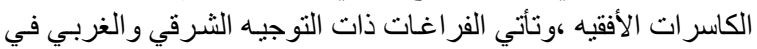

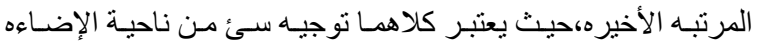
الطبيبعه. 6- إرتفاع جلسـات النو افذ لـه دور كبير في مستوي الإضـاءه مـن حيث إرتفاعه أو إنخفاضها.

• توصيات خاصه بار اسه البيئه الضوئيه:

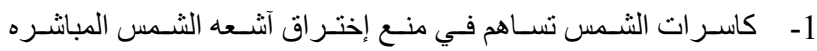
للفر اغات الجنوبيه. 2- الفر اغات الثرقيه و الغربيه لاتصلح كفر اغات تعليميه.

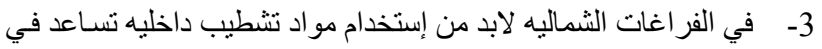

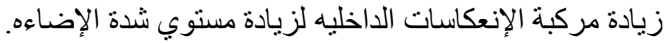

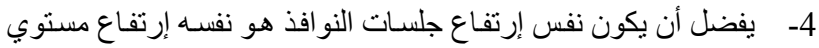

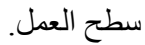

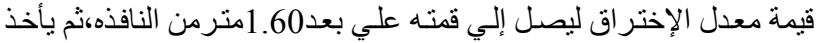

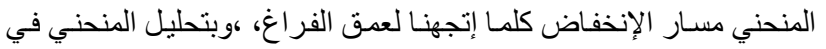

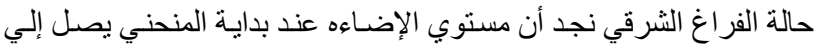

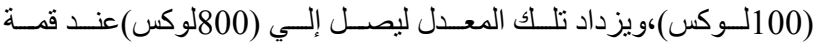

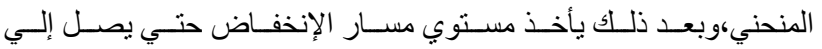

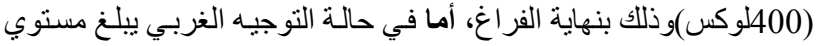

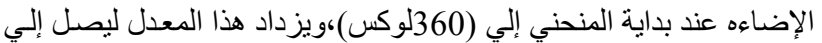

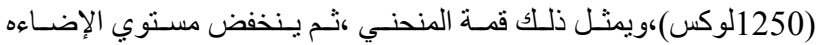
تدريجيا حتي يصل إلي (600لوكس)،وذللك في نهايـة الفراغ، كما في شكل فئل

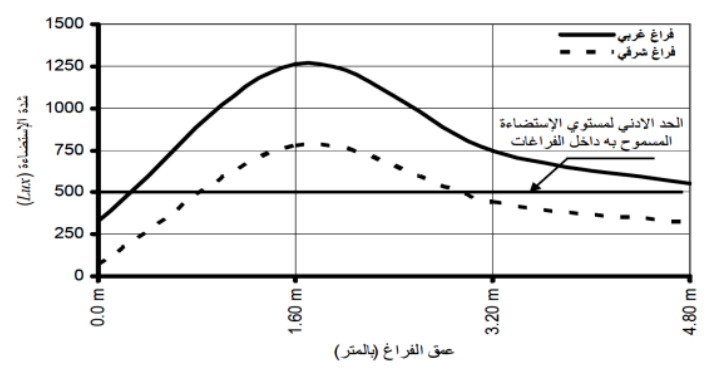

شكل(27) يوضح معدل إختر اق الإضاءه داخل الفر اغين الثرقي و الغربي

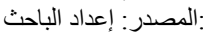

• نتائج دراسة البيئه الضوئيه للمبني محل الدراسه:

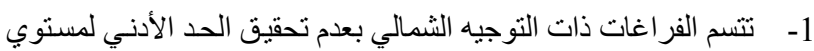

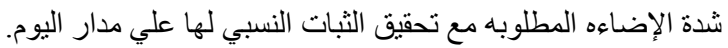

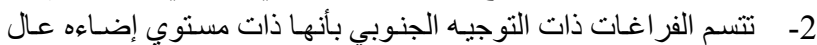

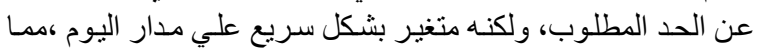

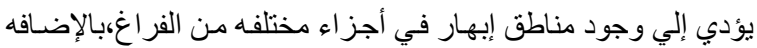

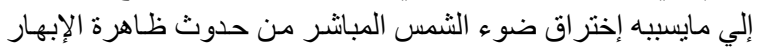

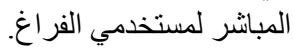

\section{المحور الثالث:كفاءه البيئه المستدامة}

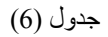

تحليل عناصر الإستدامه بالمبني محل الدراسه وتقديم الحلول المناسبه:إعداد الباحث

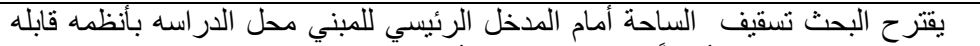

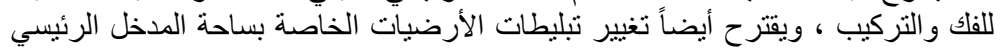

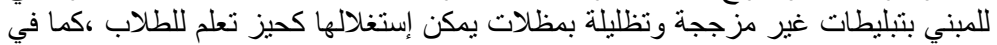

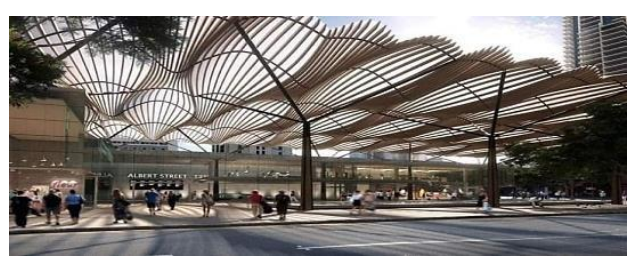

شكل(28) .

شكل (28)يوضح أسلوب التظليل بشكل أنيق لساحة مدخل المبني الرئيسي

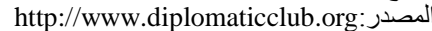

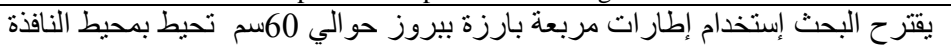

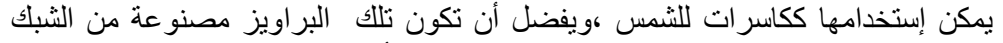

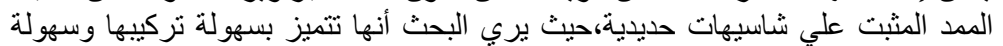

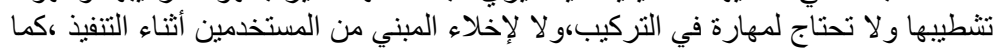

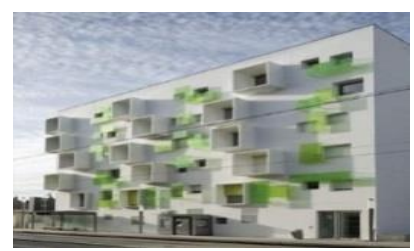

في شكل (30)

شكل(30) يوضح إستخدام كاسر ات الثمس علي النو افذ.

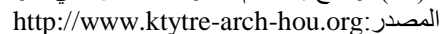

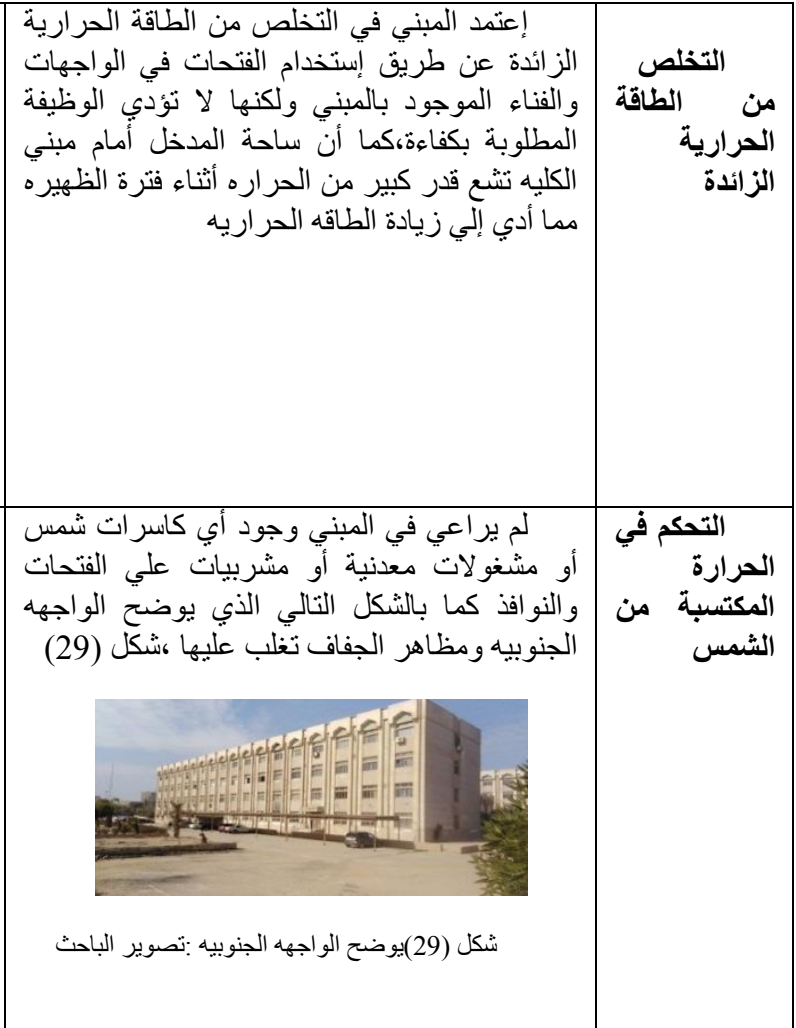


تابع جدول (6)

تحليل عناصر الإستدامه بالمبني محل الدراسه وتقديم الحلول المناسبه:إعداد الباحث

\begin{tabular}{|c|c|c|}
\hline في شكل (31) يقترح البحتخدام المراوح المحورية التي تستخدم في سحب وتمرير الهواء ،كما & 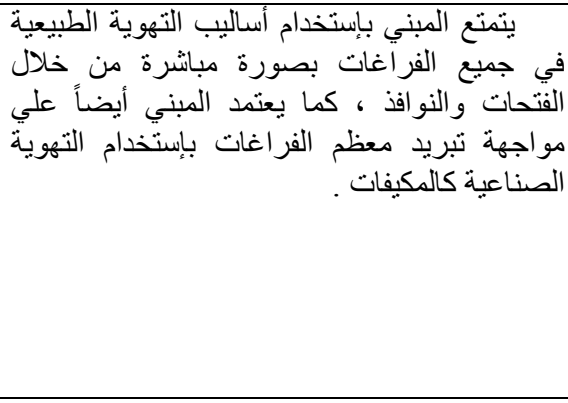 & الداخلة التهية \\
\hline 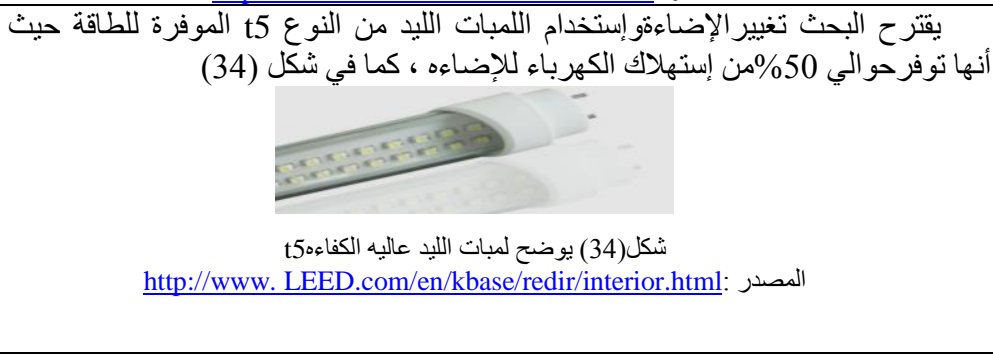 & 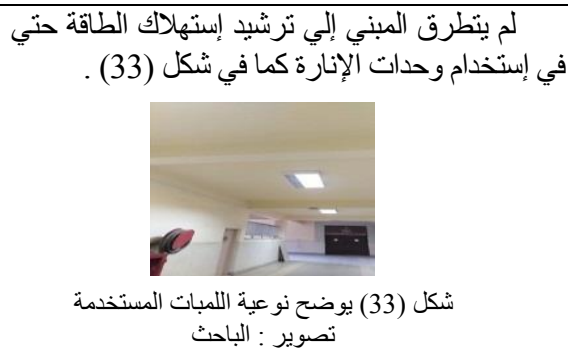 & إسترهلاتك \\
\hline 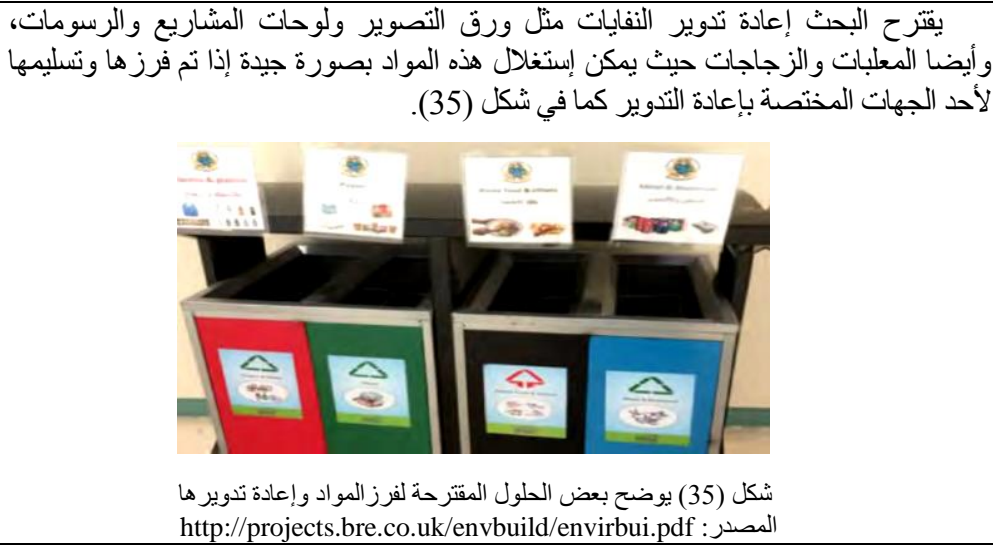 & لم يتم الاستفادة من النفايات بأي صورة. & الموارد إدارة \\
\hline 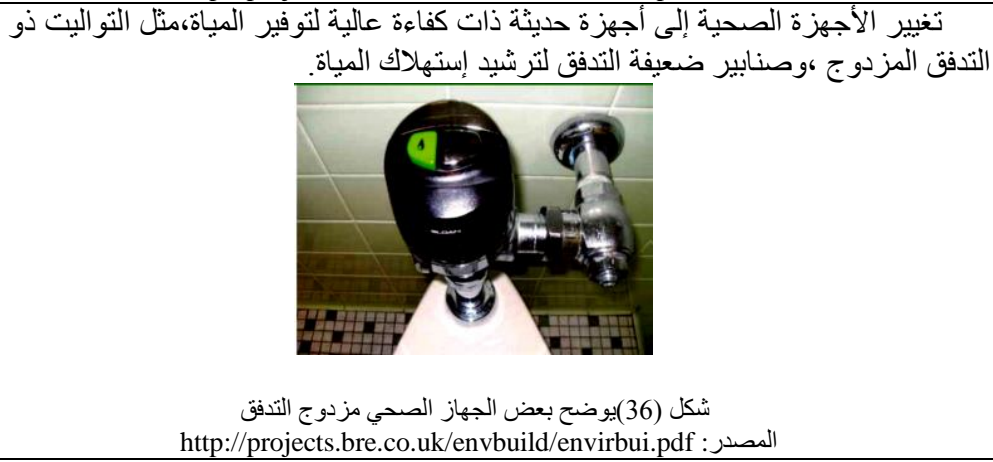 & لم ير اعي أي أسلوب للحفاظ علي المياة & علي المياة \\
\hline
\end{tabular}

\section{المحور الرابع:دراسة وضع الطاقة المستهلكة في المبني محل الدراسة}

وفيما يلي جداول توضح حساب الطاقة المستهلكة بالمبني محل الدراسة وحلول تقليلها وتحقيق الإكتفاء الذاتي:

أولا: فر اغات تعلبيه تعدل حو الي 9 اشهر في العام الدراسي وتشدل (المدرجات والقاعات الدراسبه والفصول التعليبيه والمعامل ومعامل الكمبيوتر)

جدول (7)

يوضح الطاقه المستهلكه للفر اغات النعليميه بالمبني محل الدراسه:إعداد :الباحث

\begin{tabular}{|c|c|c|c|c|}
\hline يوميا بالكيلووات المتهكة & اليومية/تقريبات التثنغيل & قالجهازبالوات & العدد العد & إسم الجهاز \\
\hline 91.4 & $\overline{8}$ & 60 & 190 & فللورسنت إضاءة \\
\hline 73.2 & 8 & 40 & 230 & وحدات إضاءة نبيون \\
\hline 39 & 6 & 50 & 130 & كمبيوتز \\
\hline 203.6 تقريبا & \multicolumn{4}{|c|}{ إجمالي الطاقة الدستهالكة يوميا } \\
\hline 5293 تقريبا & \multicolumn{4}{|c|}{ إجمالي الطاقة المستخدمة شهريا (26بوم) } \\
\hline
\end{tabular}


جدول (7)

يوضح الطاقه المستهلكه في الفر اغات الإداريه للمبني محل الدر اسه:إعداد :الباحث

\begin{tabular}{|c|c|c|c|c|}
\hline يوميا بالكيلوواتة المستهة & عدالد ساعات التشغيليل & قالوة الجهاز & العدد & إسم الجهاز \\
\hline 4.8 & 3 & 200 & 8 & ماكينات تصوير \\
\hline 100.8 & 8 & 60 & 210 & وحدات إضاءة فللورسنت \\
\hline 56 & 8 & 40 & 175 & وحدات إضاءة نبيون \\
\hline 200 & 6 & 1655 & 20 & مكيفات \\
\hline 60 & 24 & 500 & 5 & الثلاجات \\
\hline 6.75 & 3 & 150 & 15 & طابعات \\
\hline 14.4 & 3 & 400 & 12 & سخان بويلر \\
\hline 21 & 3 & 1400 & 5 & سخان مياة \\
\hline 12 & 6 & 50 & 40 & كمبيوتر \\
\hline 7.2 & 6 & 150 & 8 & شاشات تلفاز \\
\hline 1.1 & 3 & 120 & 3 & أجهزهأخري \\
\hline ل & & & & إجمالي الطاقة المستهلكة بومب \\
\hline 12585 تقريبا & & & 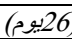 & إجمالي الطاقة المستخدمة شهر \\
\hline 151000 تقريب & & & (12) (شهر) (12) & إجمالي الطاقة المستخذمة س \\
\hline
\end{tabular}

جدول(8)

يوضح سعر تعريفة الكهرباء حاليا -يناير 2020

\begin{tabular}{|c|c|}
\hline السعر /قرش & شرائح الأستهلاكـــ.و.س /شهر \\
\hline 22 & من صفر حتي 50 \\
\hline 30 & من 51 حتي 100 \\
\hline 36 & من 101 حتي 200 \\
\hline 70 & من 201 حتي 350 \\
\hline 90 & من 351 حتي 650 \\
\hline 135 & من 651 حتي 1000 \\
\hline 145 & أكثر من 1000 \\
\hline
\end{tabular}

• جميع البيانات في النظام الشمسي إقتبسها الباحث من خلال الزيارات لعدة شركات متخصصه البات في النطات

• تطبيق الخلايا الشمسيه علي المبني محل الدراسه لترشيد الطاقه:

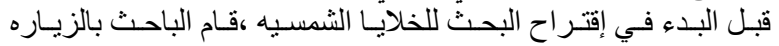

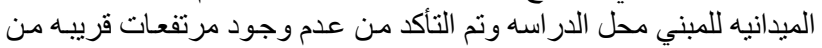

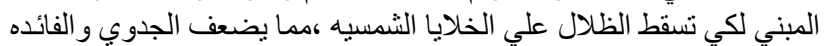

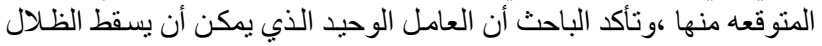

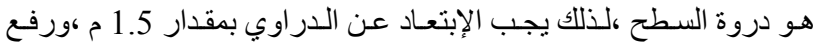

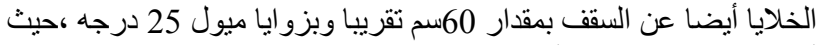

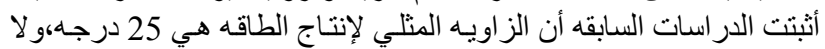

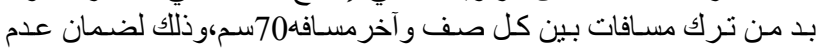

وجود ظلال طو ال فترة النهار ،كما في شكل (37)

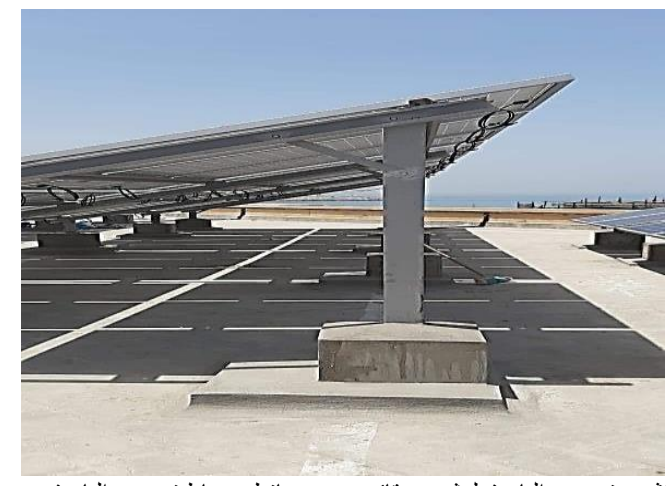

شكل (37)يوضح المسافات البينيه بين الألو احح وبعضها وركائز التثبيت:تصوير الباحث لمشروع قائم بمبني محافظه دمياط:تصوير الباحث

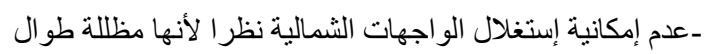

$$
\text { النهار. }
$$

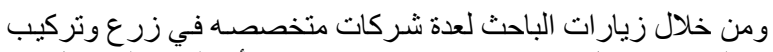

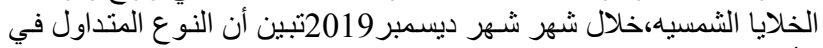

الأسواق هو النوع الموضح بالشكل الثهر التالي(38).

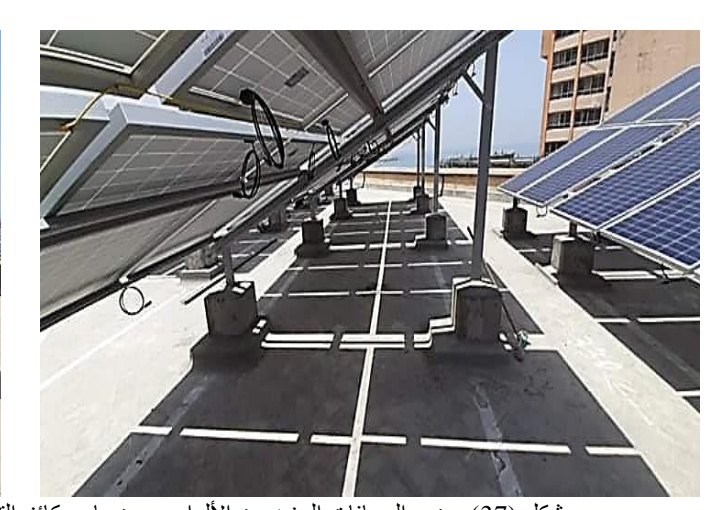

جميع البيانات بالجدول السابقة مقتبسه من خلال زيارات الباحث لثركات الأجهزه الكهربيه

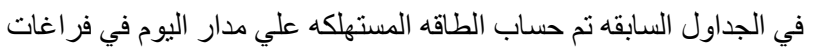
المبني محل الدر اسه من المعادله التاليه.:

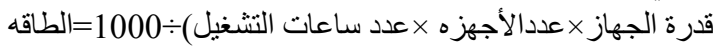

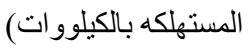

من الجداول السابقه يتضح أن:

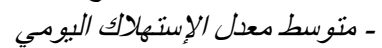
للكهرباء=6 =203.6+284=687.6كيلووات في اليوم الواحد. متوسط معدل الإستهلاك الشهري

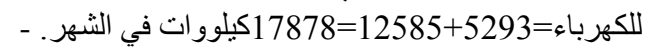
متوسط معدل الإستهلاك السنوي

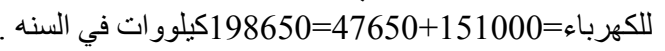

وبناء علي ماسبق يتضح أن المبني محل الدر اسه يستهلك طاقه كهربيه

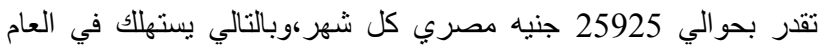
288000جنيه مصري تقريبا، حسب مايوضحه الجدول التالي لتعريفة الكهرباء لعام 2020

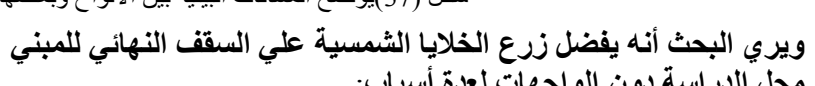

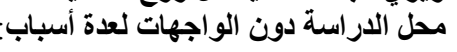

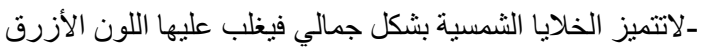

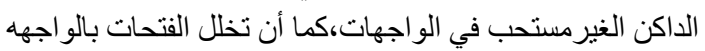

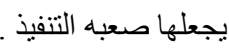

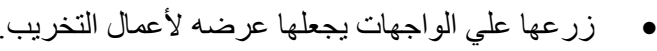
ــعدم تعامد أشعة الثمس علي الو اجهات طو ال فترة النهار. 


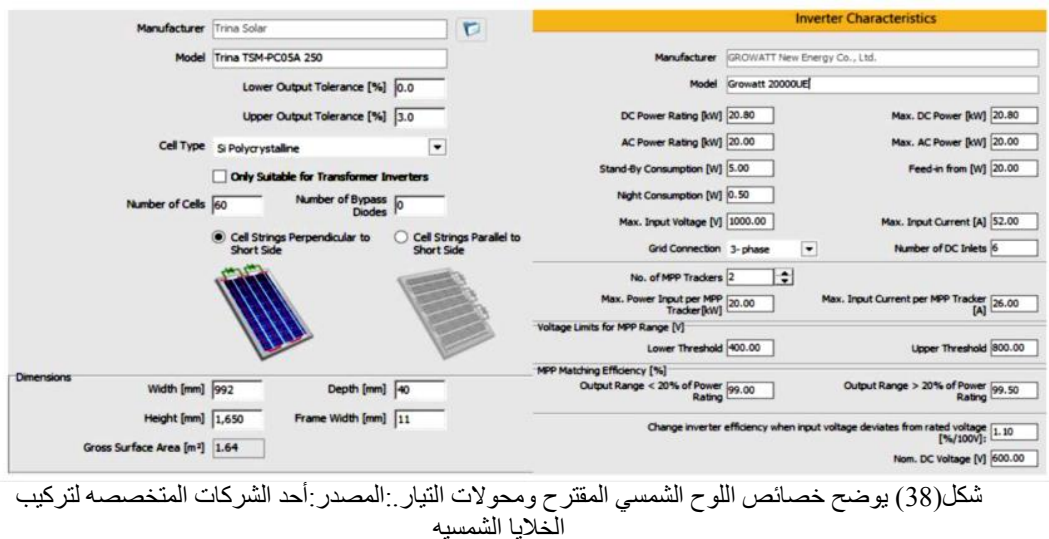

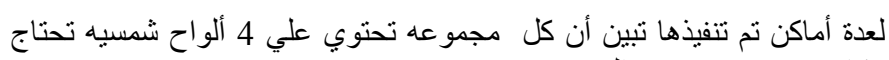

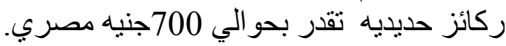

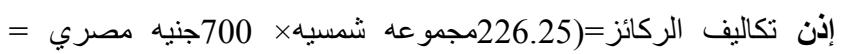

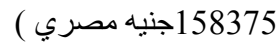

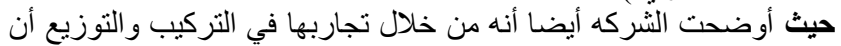

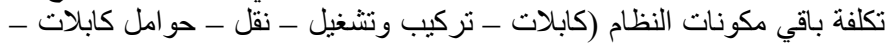

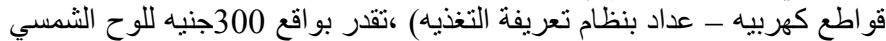

إذن تكاليف باقي المكونات تقدر بحوالي (905×300=271500 جنيه الو إحد كمًا تبين أيضا أن النظام يحتاج إلي جهاز إنفرتر يقدر بمبلغ23000جنيه

و أيضِا عدد 5 دنظمات أمبير بحو الي 25000جنيه مصري إذن إجمالي التكاليف لأول سنه بدون تكاليف الصيانه:

$25000+23000+158375+27150+525000+1221750+127400$

جنيه مصري=2107675

وفيما يلي تقدير التكلفه الإجماليه بالجنيه المصري خلال سنوات العمر الإفتراضي ومن ثم ،حساب قيمة التوفير.

جدول(9) (9) (9)

يوضح إجمالي نكاليف المشروع خلال سنو ات العمر الإفتر اضي:إعداد الباحث

\begin{tabular}{|c|c|c|}
\hline الإجمالي بالجنيه & المصري بعد التضيانه بالننيه & السنـه \\
\hline 2107675 & ------------------------- & 1 \\
\hline 21127675 & 5000 & 2 \\
\hline 2118175 & 5500 & 3 \\
\hline 2124225 & 6050 & 4 \\
\hline 2130880 & 6655 & 5 \\
\hline 213820 & 7320.5 & 6 \\
\hline 2146253 & 8052.55 & 7 \\
\hline 2155111 & 8857.8 & 8 \\
\hline 2164854.5 & 9743.6 & 9 \\
\hline 2175572 & 10717.9 & 10 \\
\hline 2187362 & 11789.7 & 11 \\
\hline 2200331 & 12968.7 & 12 \\
\hline 2214596.6 & 14265.6 & 13 \\
\hline 2230288.6 & 15692 & 14 \\
\hline 2247550 & 17261 & 15 \\
\hline 2266536.6 & 18987 & 16 \\
\hline 2287422 & 20885.7 & 17 \\
\hline 2310396 & 22974 & 18 \\
\hline 2335517 & 25271 & 19 \\
\hline 2365812 & 27798 & 20 \\
\hline 2396250 & 30577.8 & 21 \\
\hline 2400150.6 & 33635.6 & 22 \\
\hline 2437150.6 & 37000 & 23 \\
\hline 2477820 & 40700 & 24 \\
\hline 2497170 & 44070 & 25 \\
\hline
\end{tabular}

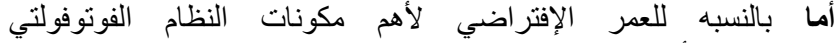

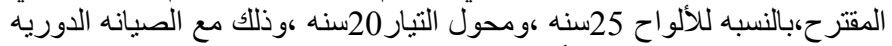

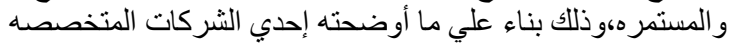

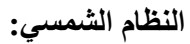
من خلال ثي اصل الباحث مع إحدي الثركات المتخصصه في مجال الطاقه

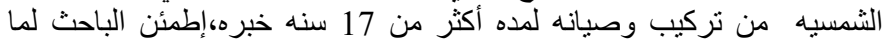
أوضحه مدير الثركه وتنبين الآتي:

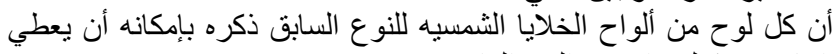

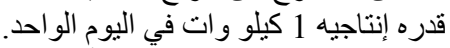

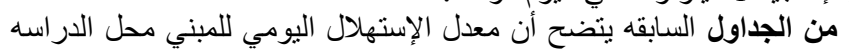

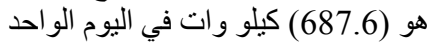

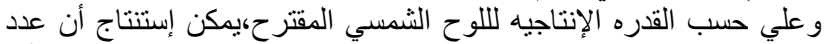

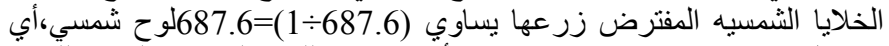

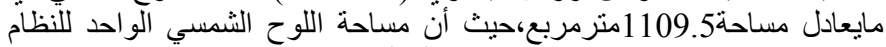

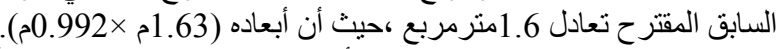

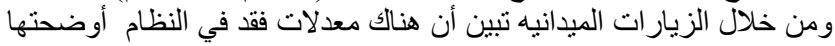
هيئه الطاقه من خلال خلأل المعادله التاليه:

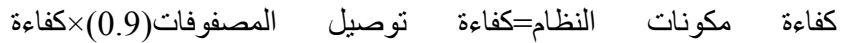

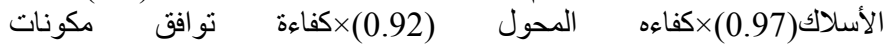

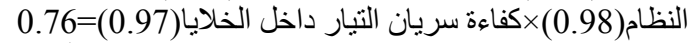

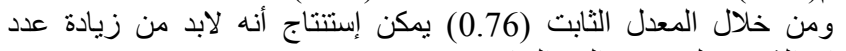

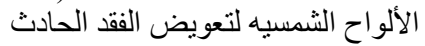

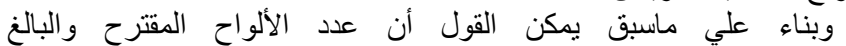

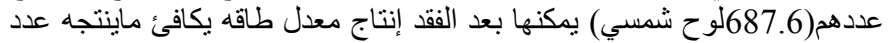

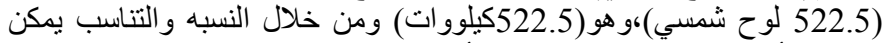

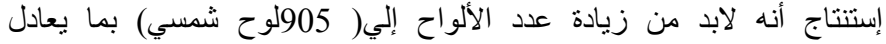
مساحة 1463منرمربع

\section{حساب تكاليف النظام الشمسي:}

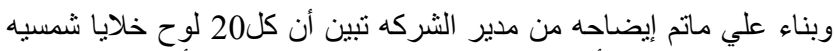

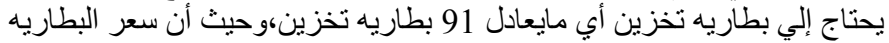
1400جنيه مصري ،إذن تقدر البطاريات بحوالي(91×1400=127400جنيه مصري)

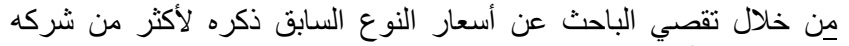

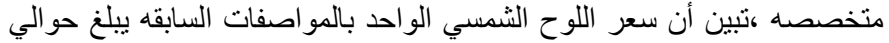

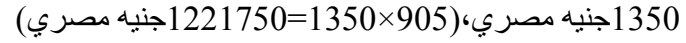

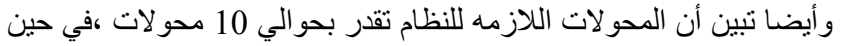

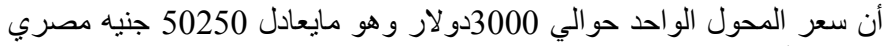

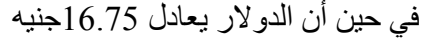
إذن سعر المحولات يقدر بحوالي(10محول×50250=525000 جناديه جنيه

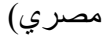
وحيث أن الألو اح تحتاج لركائز حديديه عباره عن قطاعات علي شكل زوايا

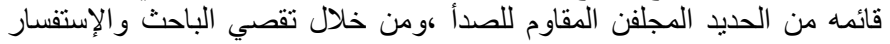




\section{المراجــ}

[1] Ran, H. (2015, December 28-29). The Investigation And Analysis On The Life-Span Of Residential Buildings. $3^{\text {rd }}$ International Conference On Education, Management, Arts, Economics And Social Science (ICEMAESS 2015), Changsha, China, 591-595.

[2] Mequignon, M., \&Haddou, H. A. (2014). Lifetime Environmental Impact Of Buildings. $1^{\text {st }}$ Ed., Cham, Springer.

[3] Wilkinson, S., Hajibandeh, M., \&Remoy, H. (2016). Sustainable Development. In M. Noguchi (Ed.), ZEMCH: Toward the Delivery of Zero Energy Mass Custom Homes, (Pp. 1-30). Cham: Springer.

[4] Manganelli, B. (2014). Economic Life Prediction of Concrete Structure. Advanced Materials Research, 919, 1447-1450.

[5] Barr, S. K.,Cross, J. E., \& Dunbar, B. H.(2017). The Whole-School Sustainability

[6] Framework: Guiding Principles For Integrating Sustainability Into All Aspects Of A School Organization. $1^{\text {st }}$ Ed., Washington, Green Building Coucnil.

العيسوي ، الحمدعلي (2003) ـ تأثير تصميم الغلاف الخارجي للمبني علي الإكتساب الحراري .

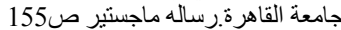

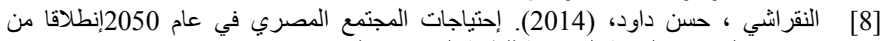

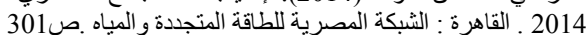

[9] Vilhena, A., Pedro, J. B., \&Paiva, J. V. (2010). Assessment Method For Buildings' Rehabilitation Needs. Development and Application.In 2010 CIB World Congress, Salford Quays (Inglaterra), 10, Salford, United Kingdom.

[10] Chandar, S. S. (2014). Rehabilitation Of Buildings. International Journal Of Civil Engineering Research, 5(4), , P. 335

[11] . Barr, S. K.,Cross, J. E., \& Dunbar, B. H. (2017). The Whole-School Sustainability Framework: Guiding Principles For Integrating Sustainability Into All Aspects Of A School Organization. $1^{\text {st }}$ Ed., Washington, Green Building Coucnil.P. 122

[12] Barr, S. K.,Cross, J. E., \& Dunbar, B. H. (2017). The Whole-School Sustainability Framework: Guiding Principles For Integrating Sustainability Into All Aspects Of A School Organization. $1^{\text {st }}$ Ed., Washington, Green Building Coucnil.P. 15

[13] -محمود، مصطفي منير.آليات تفعيل نطبيق إستخدام الطاقة الثمسية في إيجاد تنمبة حضرية

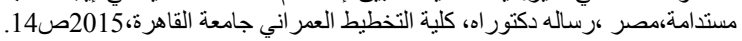

[14] Omoregie, A. D., Alabi, A. O., \&Imuetinyan, A. E. (2016). Providing Sustainability In Educational Buildings Through The Use Of Compressed Stabilized Interlocking Earth Blocks. Journal of Construction Engineering, Technology and Management, 6(2), 130-140.

[15] شرف،كمال الدسوقي.تكنولوجيا البناء المتقدمة تقييم لتجارب التطبيق في مصر.جامعة القاهره

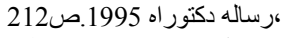

[16] محمد ماهر حسنين ،تقييم غلاف المبني ودوره في الراحه الحراريه،رساله ماجستير ،جامعه

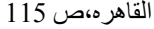

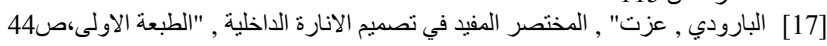

\section{Title Arabic:}

\section{إعادة تأهيل المباني التعليمية القائمة في ضوء الإستدامة}

\section{Arabic Abstract:}

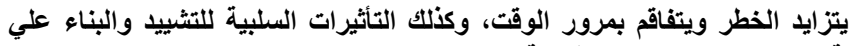

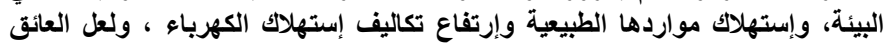

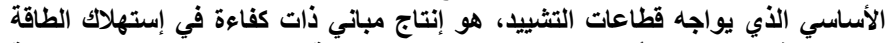

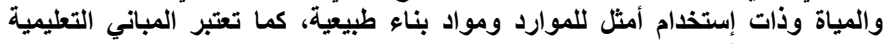

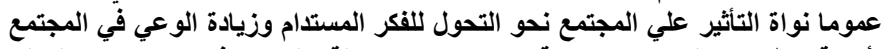

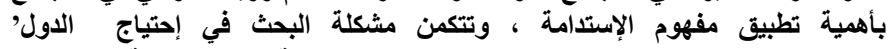

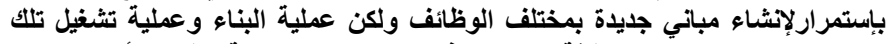

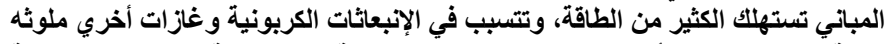

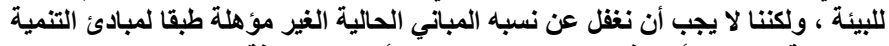

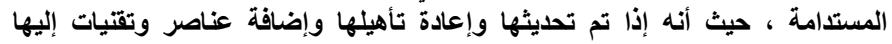

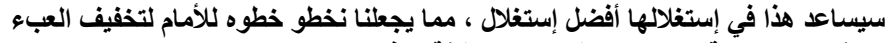

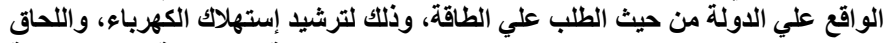

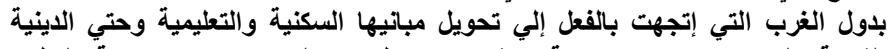
القائمة، لتصبح مباني مستدامة وتثبجيع مواطنيها علي الإبتكار ومواكبة التُوية التطور
مما سبق يمكن تحديد تكلفة المشروع بأكمله وخلال العمر الإفتر اضي

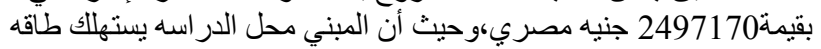
كهربيه تقدر ب288000 جنيه مصري سنويا ،إذن يمكن إسترداد التكاليف خلال 8.6

• الفوائد المباشرة للخلايا الثمسيه علي المبني محل الدراسة:

1- فوائد علي المبني محل الدراسة.

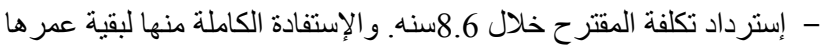

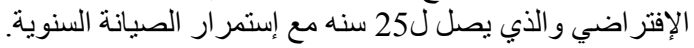
2 فوائد علي الاولة.

تخفيف ألضغط الضولة علي الشبكة العمومية وذلك من خلال الطاقة الكهربية الناتجة من هذة الخلايا. 3- فوائد بيئية.

تقليل الضرر الناتج من إستخدام مصادر الطاقة التقليدية فضلا عن نضوبها وبالتالي إرتفاع أسعار الوقود د. تولَّيد الطاقة بالمصادر المتجددة لايسبب تلوث بيئي(طاقة نظيفة) • نتائج دراسة الحالة :

أثناء مسار البحث لتحقيق أهدافة ،وجد أن من خـلال الدراسـة التحليلية للمبني

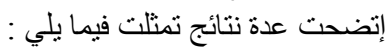

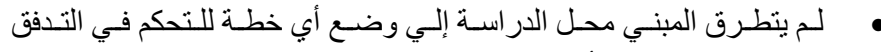

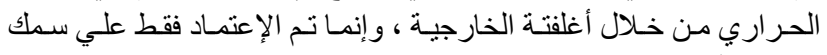
الحائط الأصلي للمبني.

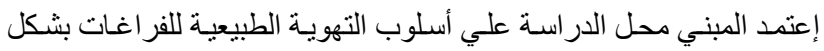

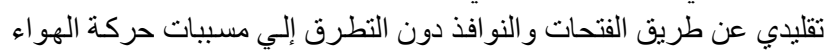

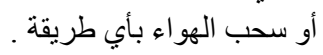
إعتمد المبني محل الدراسة في إضاءتة علي الإضلاءة الطبية الطبيعية ، و التي يمكن

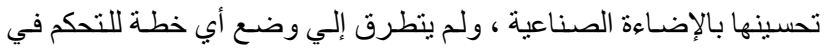
الإضاءة الطبيعية. لم ينطرق المبني محل الدر اسـة إلـي أبي إستر اتيجيات تحقق الإستـدامة في

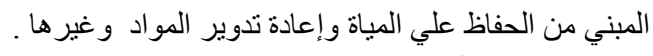

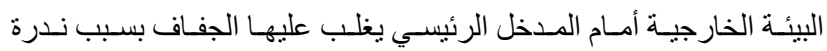
التشجيرو عدم التظليل. غياب عو امل الأمن في المبني محل الدر اسة. توصبات البحث للمختصبن بالمبني محل الدراسة: x 1- عدم إهــال الصيانة الدوريـة للمبنـي بعد نطبيق المقترحسات السـابقة للحفاظ

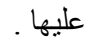
2- - تغيير اللون الخارجي للمبني محل الدراسة إلي اللون الفاتح.

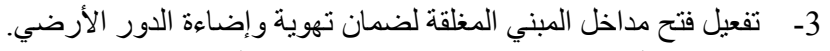

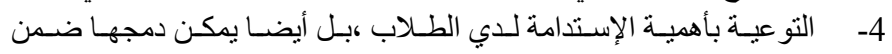
المقررات الدر اسية.

5- ضرورة الإستفادة من التجارب العملية المنفذة بالفعل في المباني التعليمية القائمة.

6- الإهتمـام بالبيئة الخارجيـة وتظليلهـا وتفعيل نظـام التعلم المفتوح ،حيث أنـه مناسب لطلبة قسم العمارة. 7- الإكثار من التشجير بالنباتات قليلة إستهلاك المياة حول المبني محل الدر اسة. 8- ت تخصيص أماكن لجمع وفرز المواد و النفايات. 